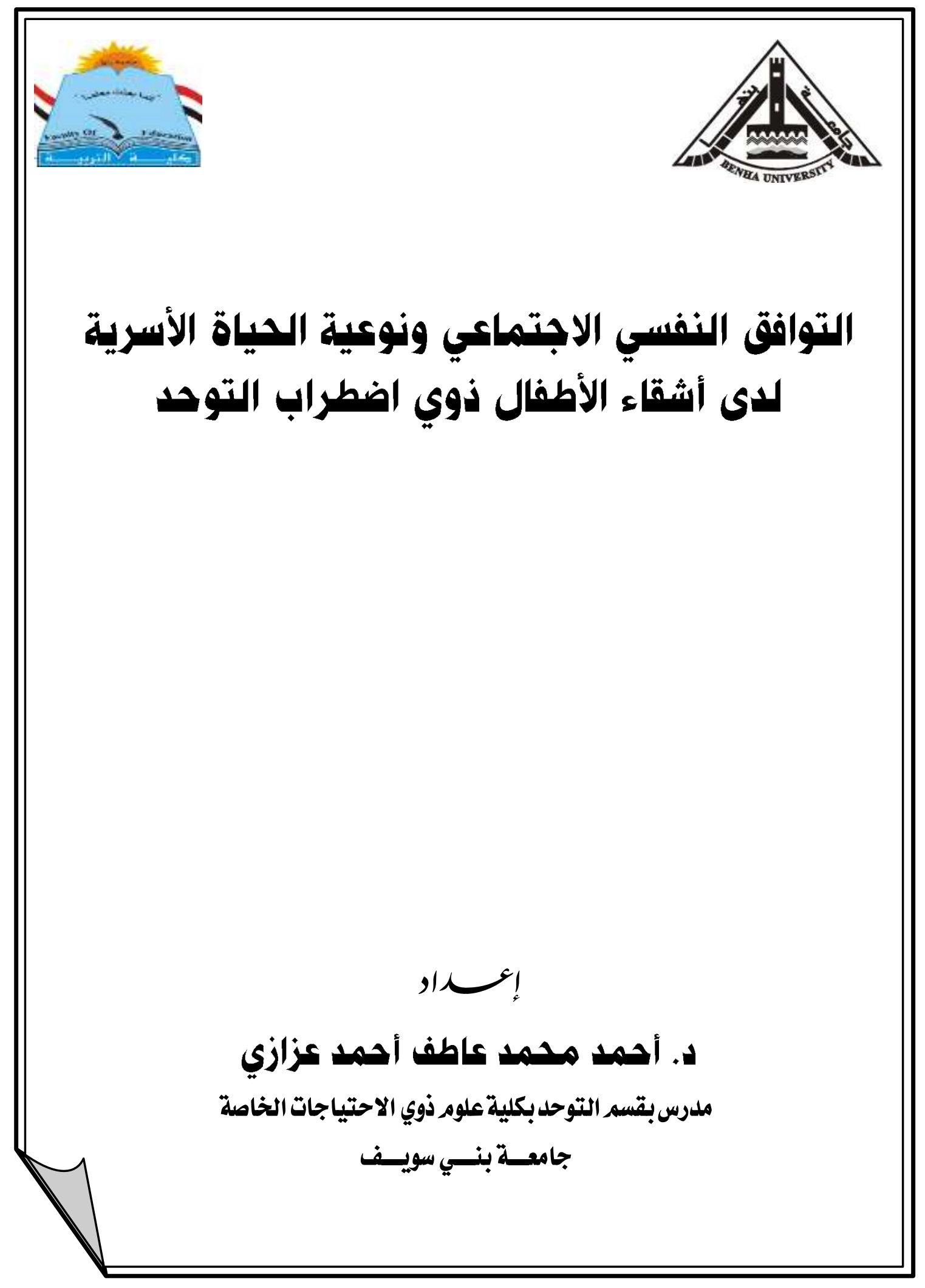




\title{
التوافق النفسي الاجتماكي ونوعية الحياة الأسرية لدى أشقاء الأطفال ذوي اضطراب التوح
}

\author{
!是
}

لد. أحمد محمد عاطف أحمد عزازي

ملرس بقسم التوحل بكلية علوم ذوي الاحتياجات الخاصة

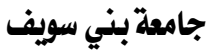

\section{المستخلم}

هدفت الدراسة الحالية التعرف على العلاقة بين التوافق النفسي الاجتماعي ونوعية الحياة

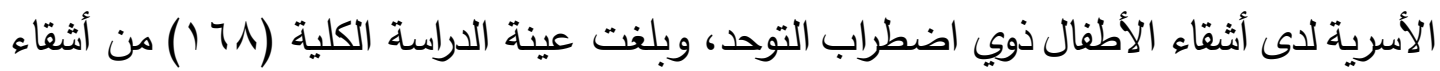
الأطفال ذوي اضطراب التوحد، واستخدت الدراسة مقياس التوافق النفسي الاجتماعي (إعداد/

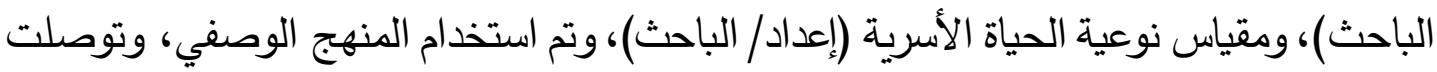

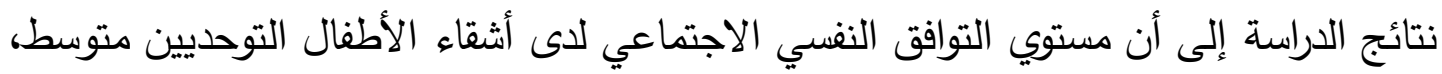

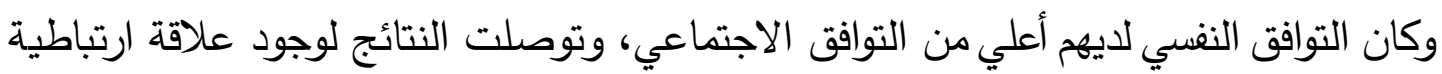
موجبة دالة احصائيًا بين التوافق النفسي الاجتماعي ونوعية الحياة الأسرية لدى أشقاء الأطفال التوحديين، وكثفت عن وجود فروق ذات دلالة إحصائية تعزي لمتغير النوع وكانت لصالح الأثقاء التهاء

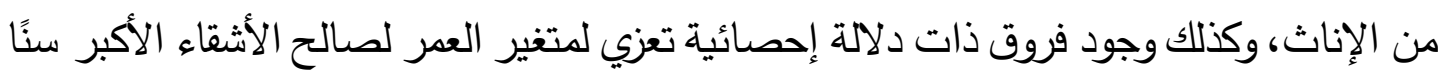

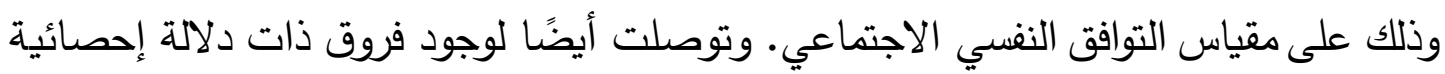

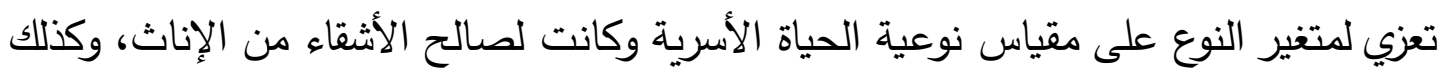

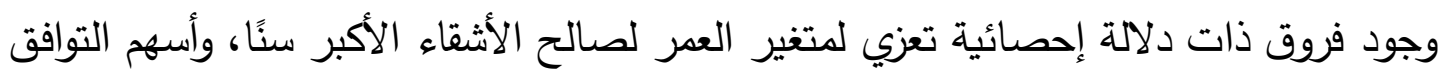

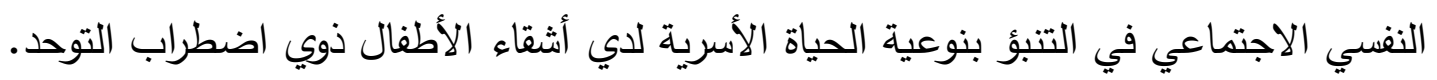
الكلمــات المفتــاحيــــة: التوافق النفسي الاجتماعي، نوعية الحياة الأسرية، أثقاء الأطفال

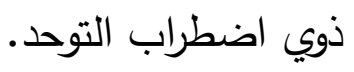




\section{Psychosocial Adjustment and Quality of family life of siblings of children with autism}

\section{Abstract}

The purpose of the study is to investigate the relationship between psychosocial Adjustment and family quality of life among a sample of siblings of children with autism, according to gender, Age. The sample of study consists of (168) male and female siblings. The researcher uses scale psychosocial Adjustment (prepared by the researcher) and the family quality of life (prepared by the researcher), as a descriptive analytical approach is used. The findings of the study show of finding a statistically significant correlation between psychosocial Adjustment and family quality of life of siblings of children with autism. The results show that there are statistically significant differences in psychosocial Adjustment in favor of females, and there are statistically significant differences in psychosocial Adjustment favor of older age. The results show that there are statistically significant differences in family quality of life in favor of females, and there are statistically significant differences in family quality of life favor of older age. as we can predict family quality of life through psychosocial Adjustment.

Key words: Psychological Adjustment, Quality of Family Life, Sibling of Children with Autism. 


\section{مة مدــــة}

يُعد اضطراب التوحد من أبرز الاضطرابات النمائية التي يُعاني منها الأطفال في فترات مبكرة من حياتها، وذلك نظرًا لغوض وشدة هذا الاضطراب فهو يشبه بلورة من الكريستال يدخل الطفل فيها لينعزل عن العالم، وكأنه في كوكب آخر، وبالرغم دن عدم وجود عـلاج لاضطراب التوحد حتى الآن، إلا أن العلاج المكثف والمبكر قدر فئه الإمكان، يمكنه أن يُحدث تغييرًا ملحوظًا وجديًا في حياة الأطفال ذوي اضطراب التوحد، وهؤلاء الأطفال يعيشون في بيئة

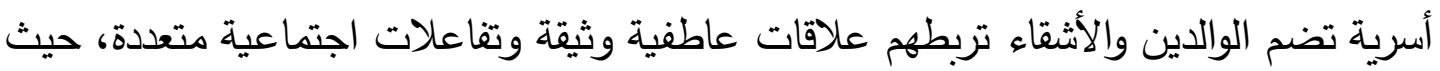

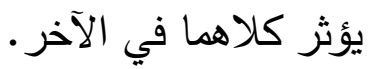

إن اضطراب التوحد هو اضطراب نمائي مُعقد ينطوي على تحديات مستمرة في التفاعل الاجتماعي واللغة والتواصل غير اللفظي والسلوكيات النمطية المتكررة (APA, 2013). وهو اضطراب عام ومنتشر يؤثر سلبًا على الأداء الوظيفي العقلي للطفل، بحيث يكون معامل ذكائه في حدود الإعاقة العقلية البسيطة أو المتوسطة (عادل عبد الله، 10 ــ4، ( ). وتُسهم الأسرة بدور كبير في التدخلات مع الأطفال ذوي اضطراب التوحد، فعلى مر

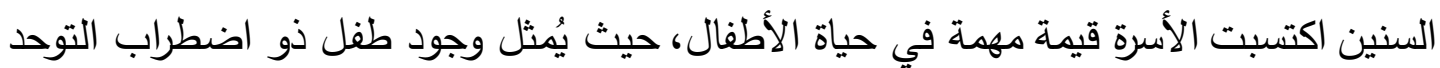

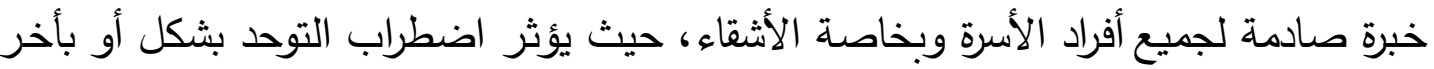

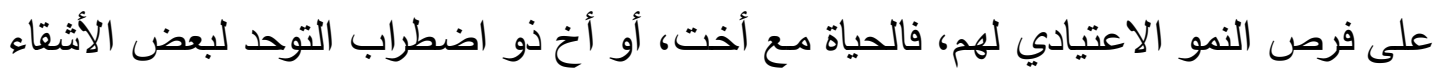

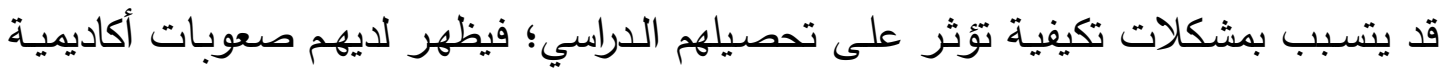

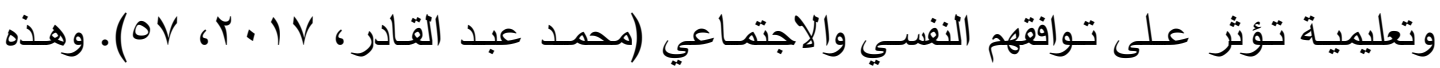
الأعراض تقف عائعًا في طريق كل من يتعامل معهم داخل الأسرة أو في المراكز والجمعيات

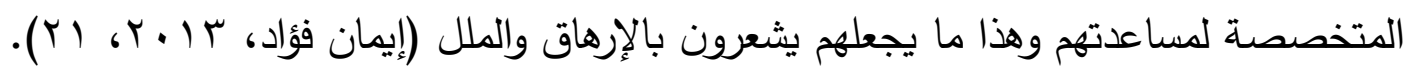
وفي الآونة الأخيرة، تزايد الاهتمام بضرورة تعديل اتجاهات أشقاء الأطفال ذوي اضطراب التوحد؛ وذلك لدورم المؤثر في حياة أقرانهم ذوي اضطراب التوحد، وباعتبارهم جزءً أساسيًا من حياة أشقائهم، فمن خلالهم يشعر الطفل ذو اضطراب التوحد بأهمية التفاعل الاجتماعي والمشاركة

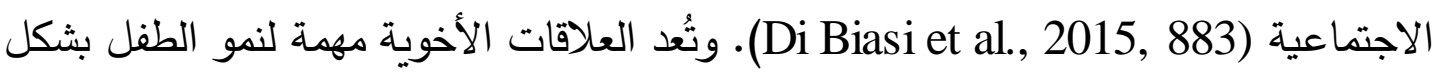


عام، وأن أشقاء الأطفال ذوي الإعاقة أكثر عرضة لسوء التوافق النفسي مقارنة بالأطفال الأصحاء ذوي النمو الطبيعي (Tsai, Cebula, \& Fletcher-Watson, 2016,116). وعلى الرغم من الجهود الرسمية وغير الرسمية التي تُبذل لتأهيل ورعاية الأطفال ذوي اضطراب التوحد إلا أن نسبة الاهتمام بأشقاء هؤلاء الفئة في جانب الرعاية محدود جدًا، وذلك على الرغم لها تتعرض له هذه الفئة من مشكلات في عملية التوافق النفسي والاجتماعي؛ مها

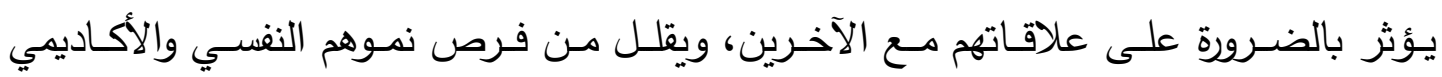

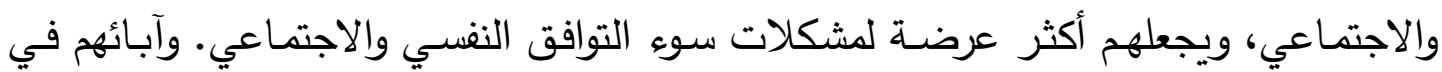
المجتمع، حيث تُعد فئة أشقاء الأطفال ذوي اضطراب التوحد من الفئات المهشة والتي تعاني من تجاهل الآباء والأخصائيين من جهة، والدراسات والبحوث العلمية من جهة أخرى. وتنعكس علاقات الأشقاء التي تتسم بالتوافق النفسي والاجتماعي على نوعية الحياة

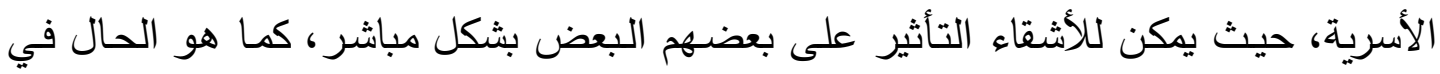

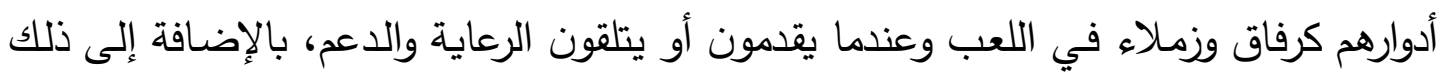
يؤثر الأشقاء على بعضهم البعض بشكل غير مباشر من خلال تأثيرهم في تفاعلات الأسرة عندما يقومون بأدوار عائلية (2015, 589) دراسة (2018) Lee, Burke, Arnold, \& Owen, أن الأثقاء البالغون للأطفال ذوي اضطراب التوحد يؤدون مجموعة متتوعة من الأدوار المختلفة في حياة أشقائهم، فهم يلعبون دورًا مركزيًا كمقدمي رعاية في المستقبل لأشقائهم الذين يعانون اضطراب التوحد؛ بالتالي فإن تمتعهم بالتوافق النفسي الاجتماعي يؤثر على نوعية الحياة الأسرية لديهم. وتُسهم نوعية الحياة الأسرية بدور مهم في تمتع الطفل بصحة نفسية جيدة، والتغلب على الفشل، والتخلص من الانفعالات السلبية، والميل نحو السعادة، وتحقيق الذات والثقـة

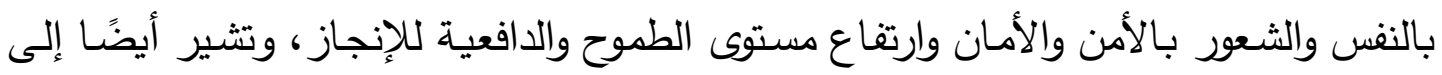
قدرة الفرد على القيام بمهامـه، وقدرتـه على مقاومـة الضـوطو والاضطرابات (جبر محمد،

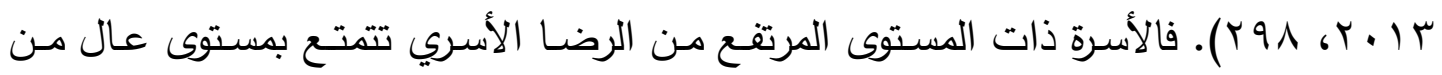
الاتصالات الأسرية، ومهارات الاتصال الإيجابية ضمن الأسرة (Olson, D., 2011,71). 
وركز مفهوم نوعية الحياة الأسرية على المهارات التي يجب أن يكتسبها الوالدين أو الأشقاء والتي تزودهم بأساليب فعالة تساعدهم على تحسين سلوك الطفل ذي الإعاقة وتدعيم

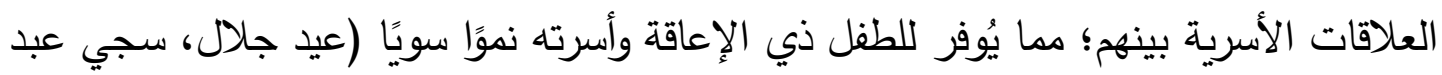

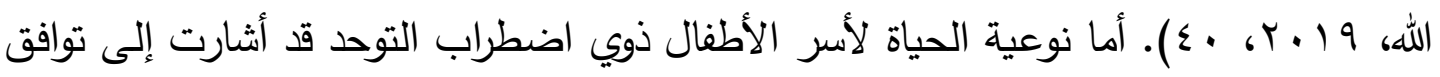

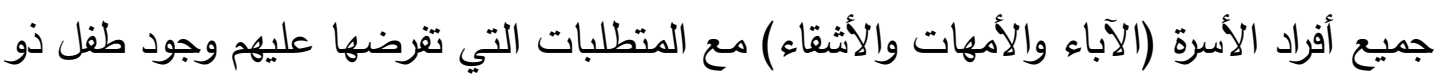

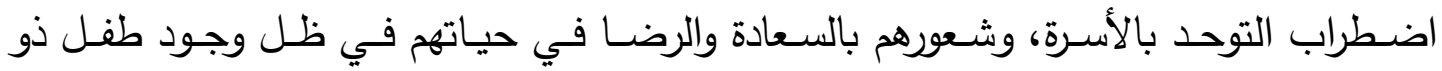
اضطراب توحد بأُسرتهم (Cholewicki, 2015, 30).

من هنا تسعى الدراسة الحالية إلى معرفة العلاقة بين التوافق النفسي الاجتماعي لاى

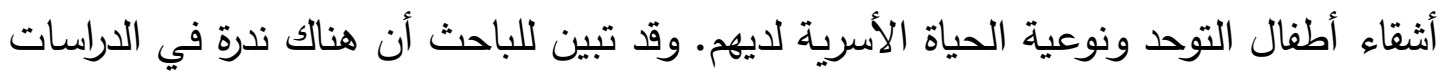

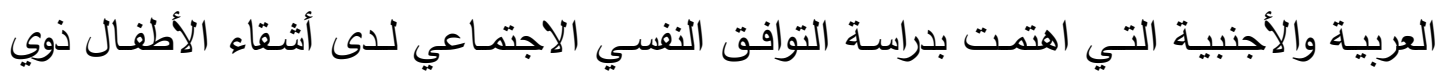

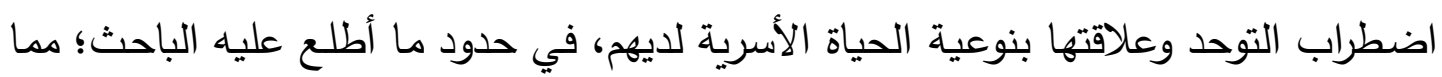
كان الدافع لديه للقيام بهذه الدراسة.

\section{مشكسـة السدراسـة}

هناك حالة من التهميش التي يعيشها أشقاء الطفل ذي الإعاقة بصفة عامة وطفل

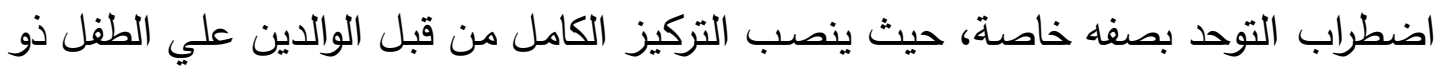

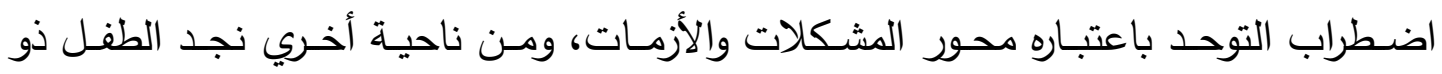

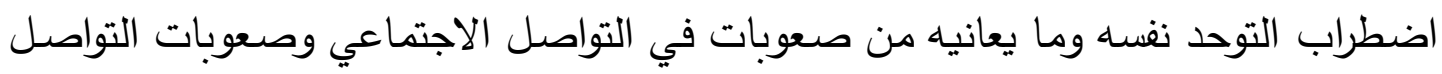
اللفظي وغير اللفظي، وعدم قدرته على إظهار التعاطف مـع الآخرين بالإضـافة إلى السلوك

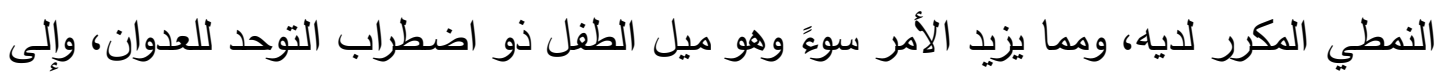

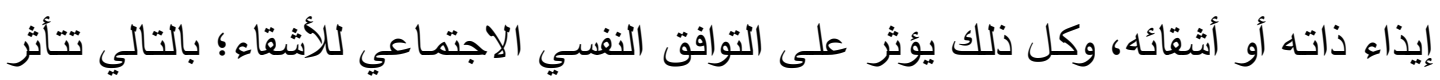

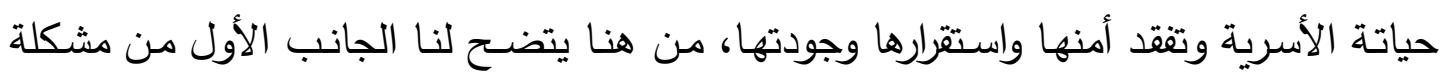

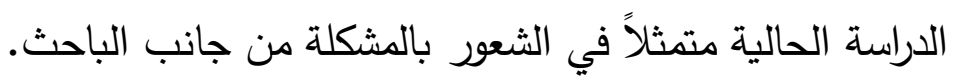

ويُعد التوافق النفسي الاجتماعي مـع وجود طفل توحد في الأسرة يتطلب كثير من

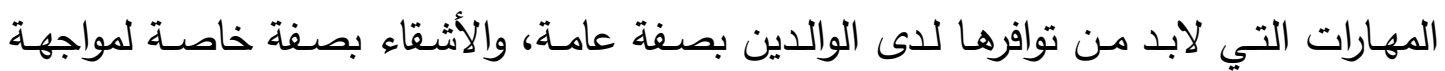

\section{riI}


متطلبات وجود طفل توحد داخل الأسرة، وإذا فحصنا بموضوعية مدى توافر الظروف المناسبة

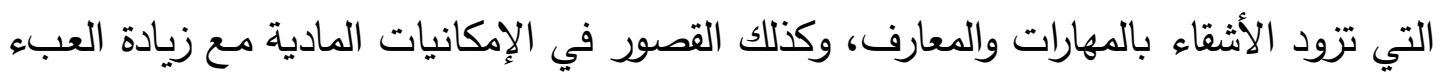
المادي، كل ذلك يمثل مصدرًا للضغوط لدى الثقيق، ويتطلب منـه تمكينًا نفسيًا يجعله قادرًا على التعامل المناسب مع هذه الظروف، وانطلاقاً من هذا الواقع وما تؤكده العديد من الدراسات بأن أشقاء الأطفال ذوي اضطراب التوحد أكثر عرضة لاضطرابات انطات نفسية اجتماعية عديدة مثل لهابل

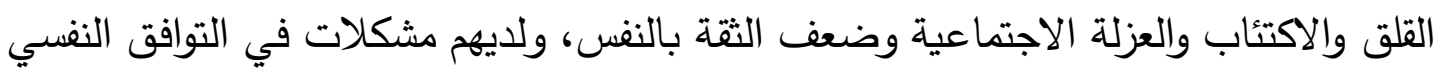

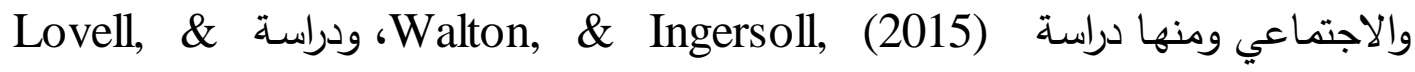

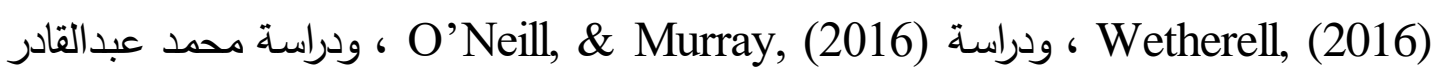

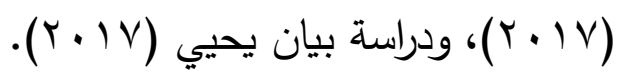

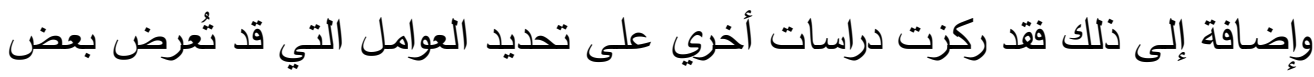

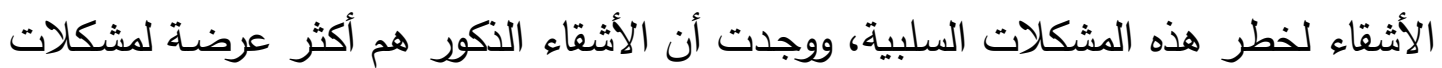

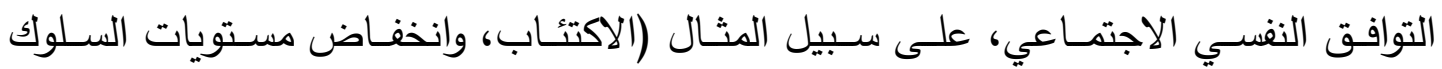

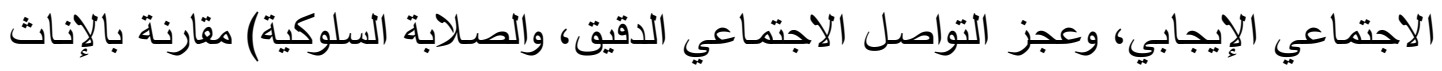
ومنها على سبيل المثال دراسة (Walton, \& Ingersoll, 2015,2). وكانت أهم النتائج التي لتئي

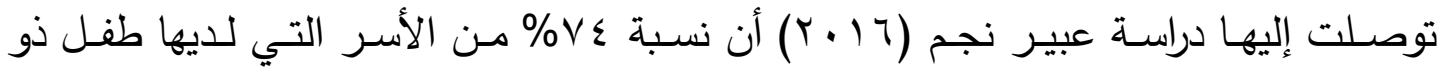

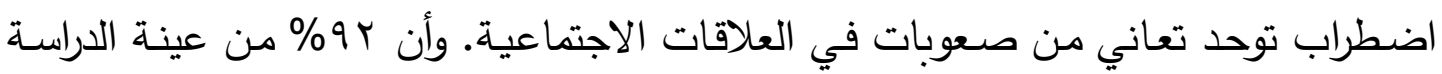

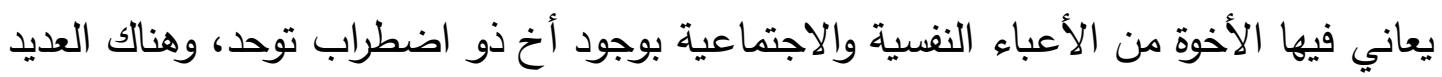

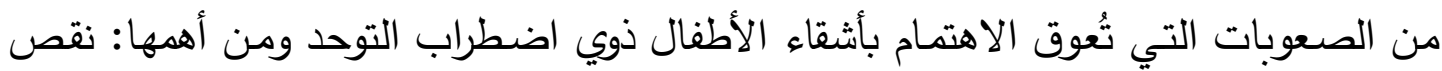

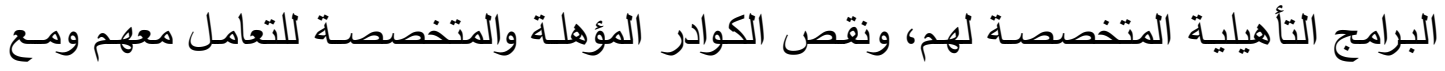

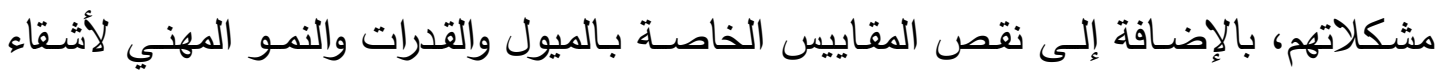

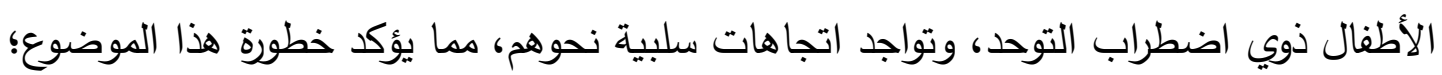
لذا كانت الحاجة ماسة لهذه الدراسة. وتبلورت مشكلة الدراسة الحالية من خلال أهمية الموضوع الذي تتناوله وهو التوافق

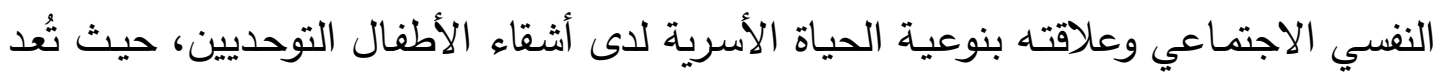

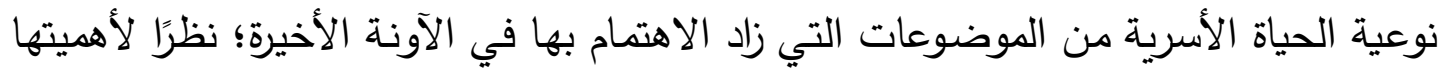


في توافق الأبناء على المستوي الاجتماعي والانفعالي والنفسي، ومن ثم رفع مستوي الصحة

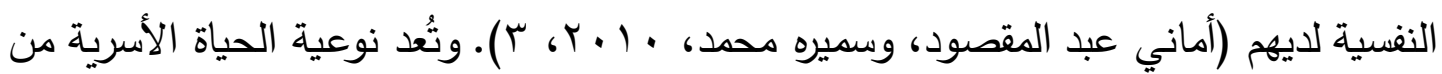

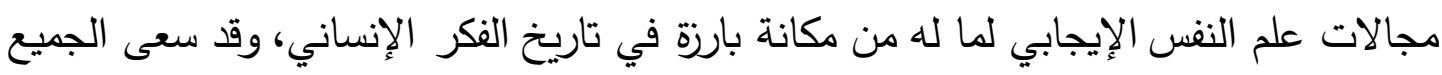

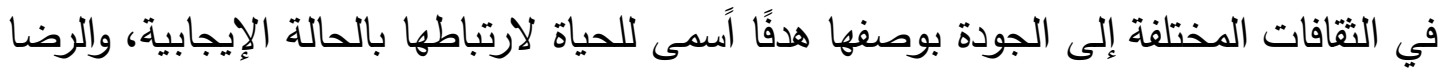
عن الحياة وجودتها وتحقيق الذات. بالإضـافة إلى ذلك فإن اضطراب التوحد يُعد من ضمن اضطرابات النمـو الثـامل، والذي يتميز بضـفـف مهارات التواصـل الاجتمـاعي والسـلوكيات

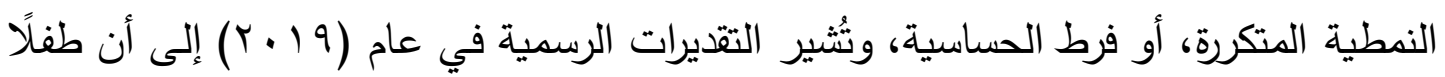

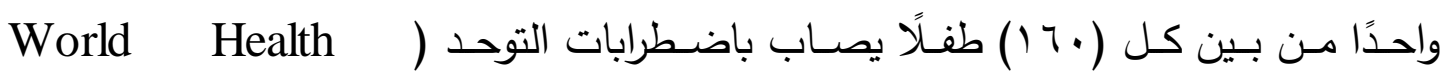

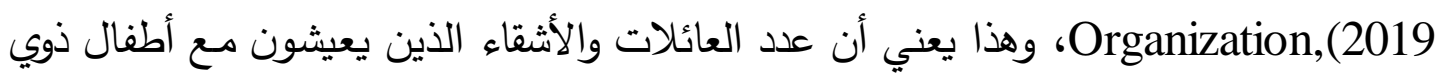
اضطراب التوحد قد زادت أيضًا بشكل كبير، بالتالي فهم بحاجة إلى مزيد من الاهتمام والرعاية. كما تبينت مشكلة الدراسة في ندرة الدراسات التي حاولت ربط متغيري الدراسة الحالية معًا وخصوصًا الدراسات التي أجريت في البيئة العربية، حيث تؤكد دراسة دي بياسي وآخرون على أن التوافق النفسي الاجتماعي لأشقاء الأطفال التوحديين Di Biasi et al., (2015) مجالًا حديثًا نسبيًا؛ ولأن الأبحاث والدراسات هي السبيل للتعرف على التوافق النفسي الاجتماعي ونوعية الحياة الأسرية. وبناءً على ما سبق يمكن صياغة مشكلة الدراسة في الأسئلة التالية: 1-ما مستوى التوافق النفسي الاجتماعي لاى أشقاء الأطفال التوحديين؟ ץ-مـا نوع العلاقـة بين التوافق النفسي الاجتمـاعي ونوعيـة الحياة الأسـرية لدى أثـقاء

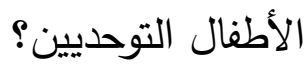

ז- هل يختلف التوافق النفسي الاجتماعي باختلاف (النوع، والعمر) لدى أثقاء الأطفال التوحسين؟ ع - هل تختلف نوعية الحياة الأسرية باختلاف (النوع، والعمر ) لدى أشقاء الأطفال التوحديين؟ 0- ما مدى إسهام التوافق النفسي الاجتماعي في التنبؤ بنوعية الحياة الأسرية لدي أثقاء الأطفال التوحديين؟ 


\section{أهـــاف الــدراســة}

\section{سعت الدراسة الحالية إلى تحقيق الأهداف التالية:}

1-قياس مستوى التوافق النفسي الاجتماعي لدى أشقاء الأطفال ذوي اضطراب التوحد. ץ- التعرف على العلاقة بين التوافق النفسي الاجتماعي ونوعية الحياة الأسرية للى أشقاء

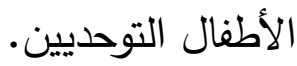

r-تحديد الفروق في التوافق النفسي الاجتماعي لاى أثقاء الأطفال التوحديين حسب كل

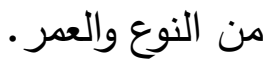
ـ - تحديد الفروق في نوعية الحياة الأسرية لدى أشقاء الأطفال التوحديين حسب كل من

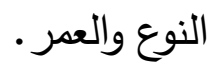
ه-معرفة إسهام التوافق النفسي الاجتماعي في التتبؤ بنوعية الحياة الأسرية لاى أشقاء

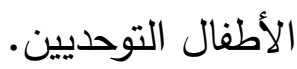

\section{أهميسية الــدراسـة}

تتحدد أهمية هذه الدراسة في ذلك الجانب الذي تتصدى لدراسته وهو الكثف عن مدى

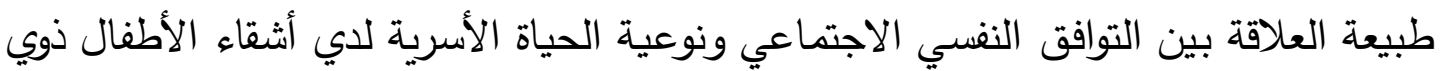
اضطراب التوحد، ويُكن أن تتضح أهية الدراسة الحالية كما يلي:

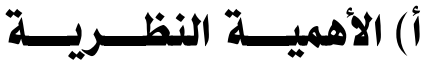

تسـي الدراسـة لإثراء الجانـب المعرفي من خلال تقديم المزيــــــن المعلومـات حـول التوافق النفسي الاجتماعي ونوعية الحياة الأسرية لدي أثقاء الأطفال التوحديين؛ حيث إنه من

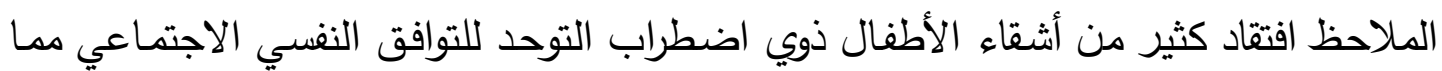
يجعلهم يفقدون الثعور بنوعية الحياة الأسرية لديهم.

أهمية الدور الذي يمكن أن يقدمه التوافق النفسي والاجتماعي في تحقيق نوعية الحياة

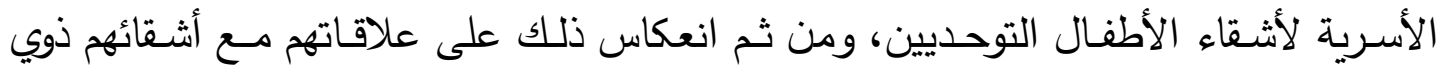

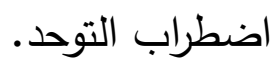


تأتى الدراسة الحالية كاستجابة موضوعية للعديد من توصيات البحوث والمؤتمرات، وما

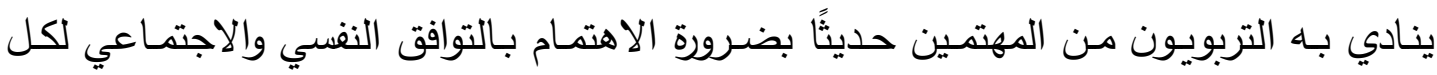
المحيطين بالطفل ذو اضطراب التوحد: لما له من أثر بالغ على نوعية الحياة الأسرية. ندرة الإسهامات السيكولوجية العربية والأجنبية في (حدود علم الباحث) من حيث دراسة العلاقة بين التوافق النفسي والاجتماعي ونوعية الحياة الأسرية لديهم.

\section{ب) الأهميـة التطبيقيــة}

تسعي الدراسة الحالية لتقديم صورة وصفية لموضوع التوافق النفسي الاجتماعي وبيان علاقته بنوعية الحياة الأسرية؛ مما يُعمق الدراسات الميدانية في هذا الثأن. تسـاعد الدراسـة على تمكين العـاملين (أخصـائيين، ومعـالجين) بمجـال الإعاقـة مـن الإستفادة من مقاييس الدراسـة في تعاملهم مـع الأطفال ذوي اضطراب التوحد وأسرهم بصفة لإنة عامة وأشقائهم بصفة خاصة. نتائج الدراسة تُسهم في طرح بعض التوصيات التي تساعد في تقديم برامج إرشادية لتنمية الجانب الإيجابي (التوافق النفسي الاجتماعي، نوعية الحياة الأسرية) لدي أثقاء الأطفال

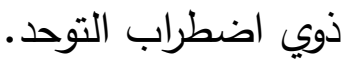

\section{التعريفات الإجرائية لمصطلحات الدراسة}

يعرض الباحث التعريفات الإجرائية لمصطلحات الدراسة وهي:

\section{- التواقق النفي الاجتماعي: Psychosocial Adjustment :}

هو: "عملية ديناميكية تظهر في مدي رضـا الفرد عن نفسهاه وعن الآخرين، وإقامته علاقات اجتماعية، وامتثاله لقواعد الضبط الاجتماعي، وفيه تكون حاجات الفرد ومنطلبات البيئة مشبعة تمائًا من خلال علاقة منسجمة بين الفرد وبيئته الاجتماعية. ويُعرف إجرائيا بأنه: "الدرجة التي يحصل عليها شقيق الطفل ذو اضطراب التوحد على مقياس التوافق النفسي الاجتماعي المُعد في الدراسة الحالية". 


\section{• نوعية الحياة الأسرية: Quality of family life :}

هي الفاعلية في القيام باحتياجات الأسرة وتمتع أعضائها بحياتهم معًا كأسرة متتاغمة وامتلاك الفرصة لنوعية الحياة الأسرية وهي: التفاعل الأسري، ومهارات الحياة اليومية، والحالة

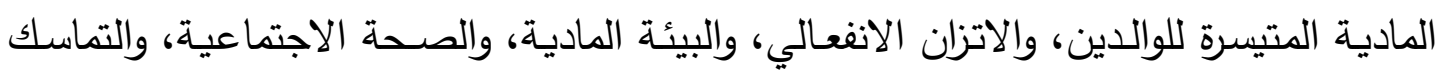

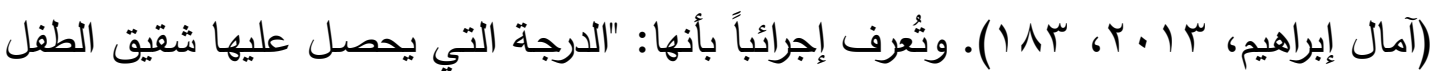
ذو اضطراب التوحد على مقياس نوعية الحياة الاسرية المُعد في الدراسة الحالية".

\section{الإطسـار النظـــري للــدراسـة}

تتضمن الدراسة الحالية مجموعة من المتغيرات وهي التوافق النفسي والاجتماعي ونوعية الحياة الأسرية لأثقاء الأطفال ذوي اضطراب التوحد، ويمكن تتاول هذه المتغيرات على النحو التالي:

\section{أ) التوافق النفسي والاجتماعي}

اهتم العديد من المتخصصين في علم النفس والصحة النفسية في السنوات الأخيرة

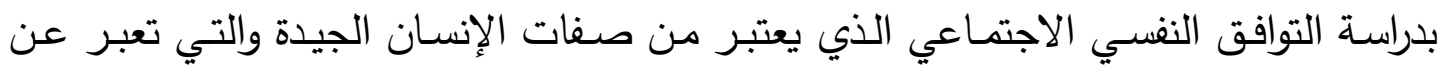

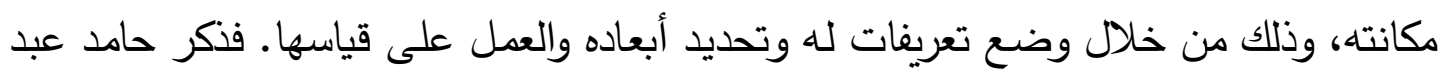

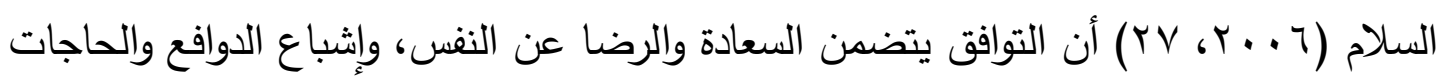

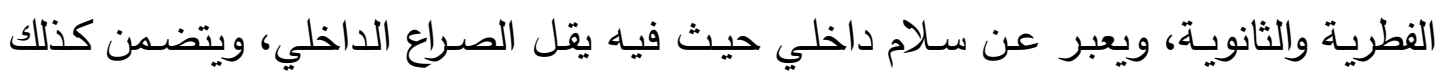
التكيف مع مطالب النمو في مراحله المتتابعة.

ورأت زينب شقير (r....r، 0) أن التوافق الثخصي هو" قدرة الطفل على تقبله لذاته

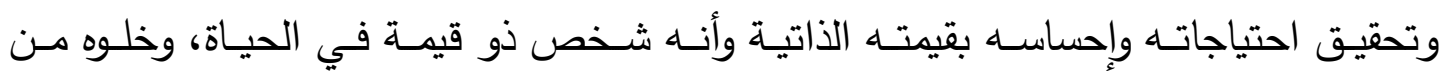

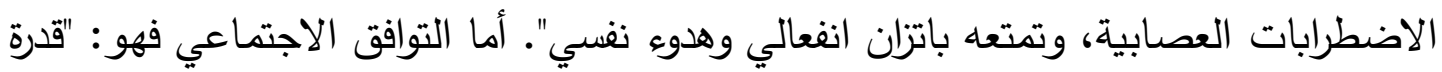

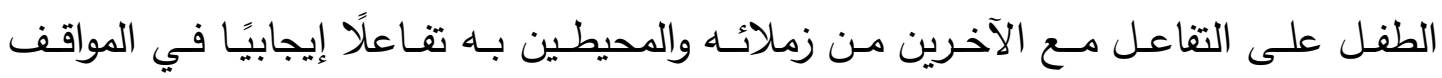
الاجتماعية المختلفة، وذلك من خلال المشاركة والتعاون في الأنثطة التي يمارسها معهم، أو الو

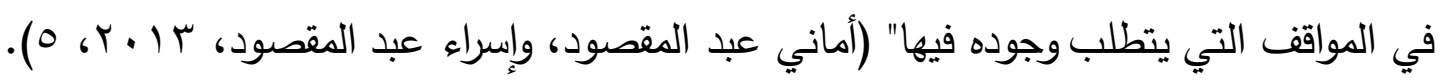
وعُرف التوافق النفسي والاجتماعي في موسوعة علم النفس والتحليل النفسي: بأنه كل سلوك أو نثـاط يقوم بـه الإنسان يهدف منـه تحقيق نجاحاً في مواقف حياته المختلفة، فهو 
يتضمن إثباعًا لحاجات الفرد ودوافعه بصورة لا تتعارض مع معايير المجتمع وقيمه (فرج عبد

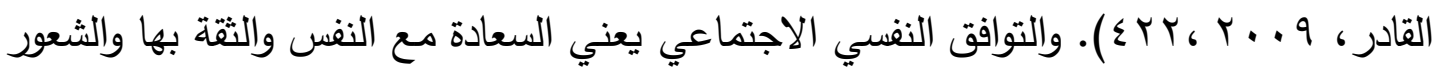

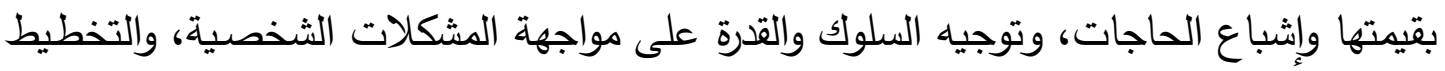
والسعي لتحقيق الأهداف، وتغيير الظروف البيئية بما يحقق الأمن النفسي. وعرف Rodriguez-Fernandez et al., (2016) التوافق النفسي الاجتماعي على أنه:" الكفاءة النفسية والاجتماعية التي تُساعد الفرد على النجاح في أداء المهام المطلوبة منـه

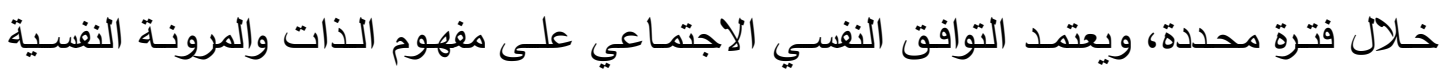

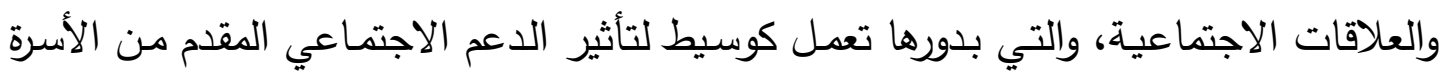

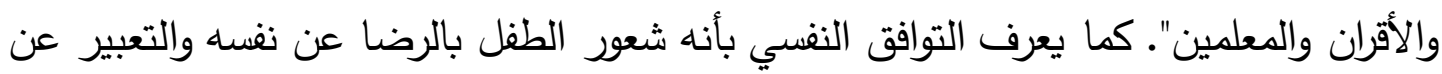
مشاعره وآرائه بطريقة مناسبة وامتلاكه درجة مناسبة من الثبات الانفعالي (أماني عبد المقصود، بعدئ

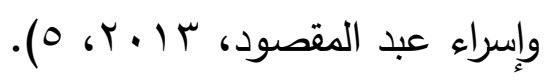
ويُنظر إلى التوافق على أنه عملية ديناميكية فيها تفاعل الفرد مع محيطه من جهة،

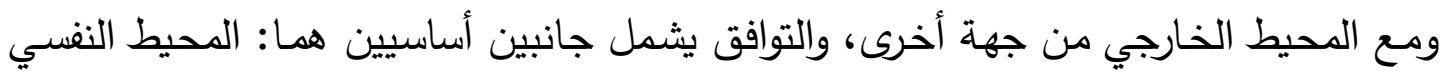
الداخلي وهو يشمل البناء النفسي للفرد من دوافع وميول وعواطف، والدحيط الخارجي وهو البيئة المحيط بالفرد سواء كانت بيئة طبيعية واجتماعية (Alanani, 2000). ومجالات التوافق عديدة فمنها (التوافق الدراسي، والتوافق المهني، والتوافق الجنسي،

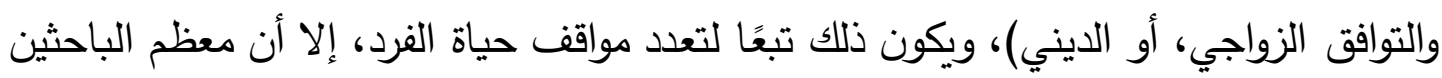

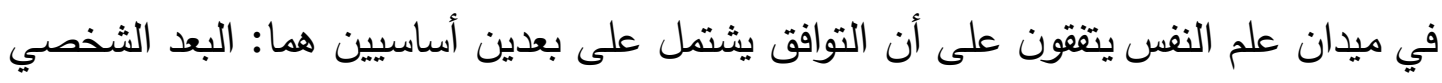

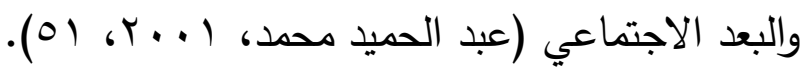
وتبـرز التأثيرات الخاصـة بوجـود طفل ذي إعاقـة في الأسـرة على التوافق النفسـي

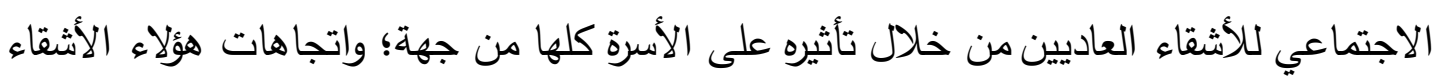

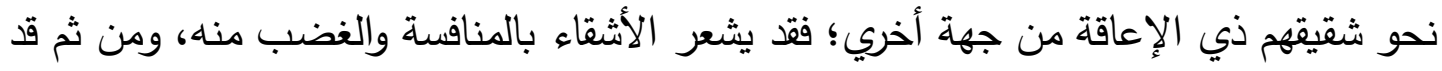

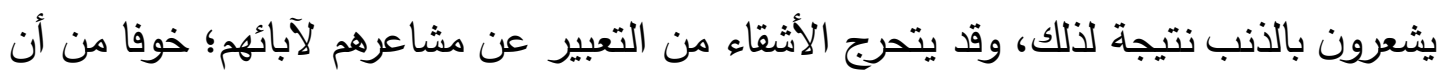

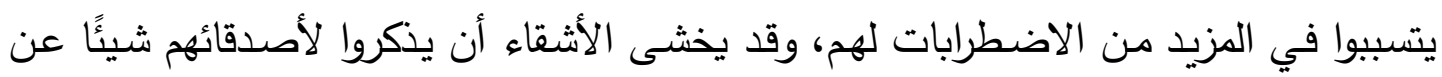


شقيقهم ذي الإعاقة ، وما تعانيه منه الأسرة بسببه؛ خوفا من أن يتعرضوا لنبذهم أو سخريتهم،

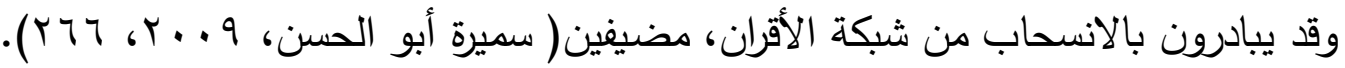
وهنـاك عوامـل عديـدة تؤثر على التوافق النفسي الاجتمـاعي لــى أشقاء الأطفـال

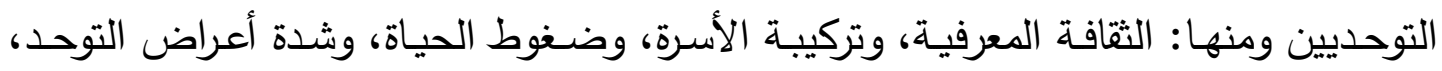
والـدعم الاجتمـاعي، وتظهر بصـورة واضـحة في العلاقـات السـلوكيات والعواطـف والإدراك والمشاركة (McHale, Updegraff, \& Feinberg, 2015, 589). والأطفال ذوي اضطراب التوحد يظهرون مجموعـة من السلوكيات التي تؤثر على

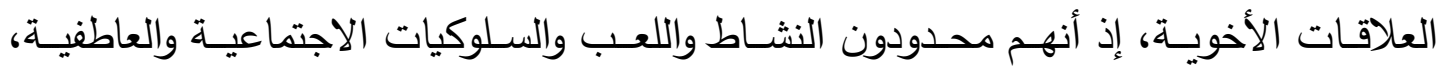
وتواصلهم البصري ضعيف، ولديهم اضطرابات في التواصل وغير منسجمين اجتماعيًا ولديهج

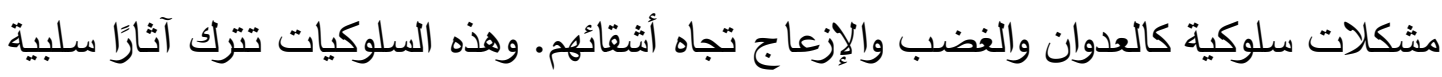
على سلوك الأشقاء العاديين ومفهومهم نحو ذواتهم، حيث يعانون من الوحدة والمشاحنات،

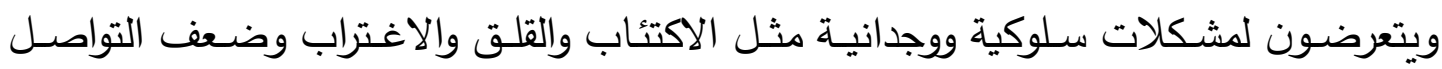

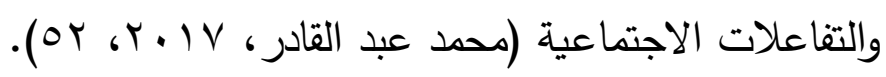

\section{ب) نوعية الحياة الأسرية لأشقاء الأطفال ذوي اضطراب التوحد}

إن بداية ظهور مصطلح نوعية الحياة في مجال الدراسات النفسية كان مرتبط بالأفراد

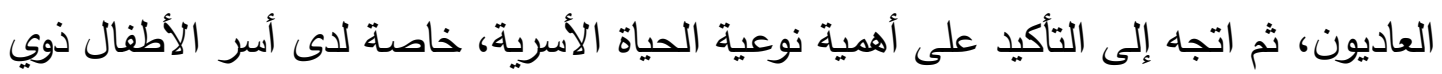

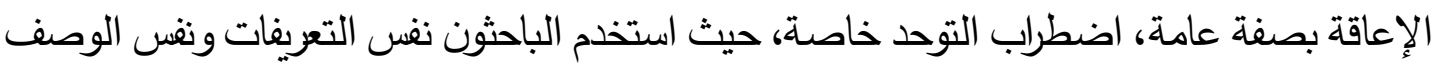

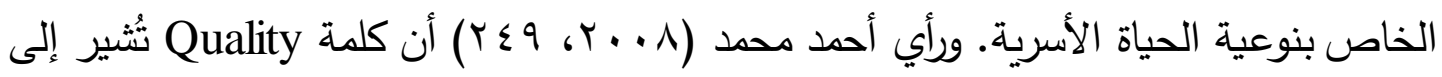
خواص أو صفات معينة في موضوع ما، وهو يتضمن هنا قطبي هذه النوعية، أحدهما جيد يعكس الحس

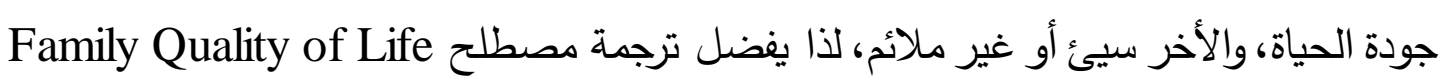
هنا بنوعية الحياة الأسرية، وليس جودة الحياة الأسرية، كما يري بعض البر الباحثين.

وتُعتبر نوعية الحياة الأسرية من الأمور التي اهتم بها مجال التربية الخاصة بالدراسة

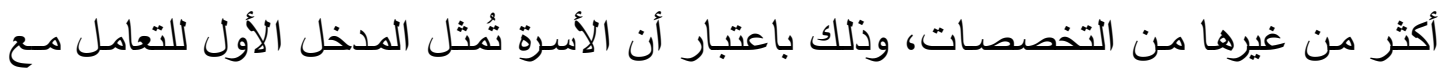

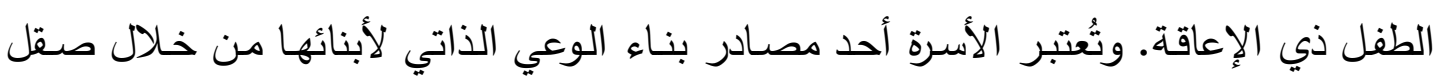


شخصيتهم، وتنمية وعيهم الذاتي الإيجابي لمواجهة مشكلاتهم، ومساعدتهم على التمييز بين ما هو صحيح وما هو خاطئ، حتى يتمكنوا من التقاعل مع مشكلاتهم الحياتية بشكل إيجابي، ويتجاوزون الصعائب (Ierardo, 2017).

وانطلاقا من قاعدة نوعية الأسرة من نوعية الحياة، باعتبار أن الأسرة تنظيم له بناءه

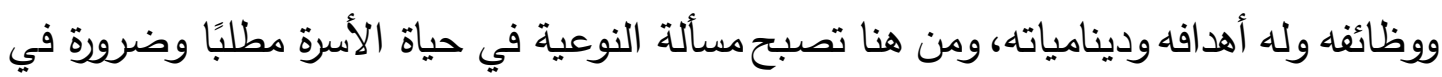

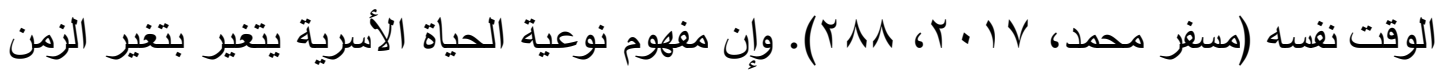

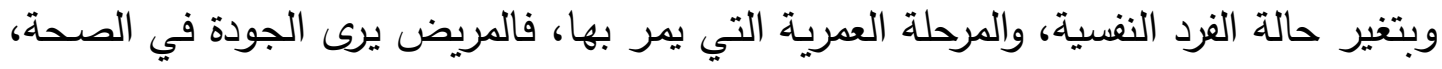

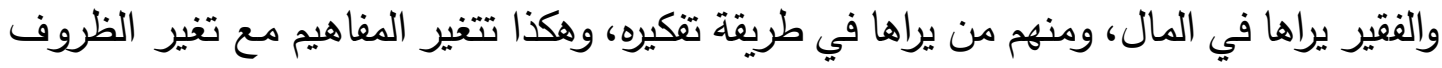

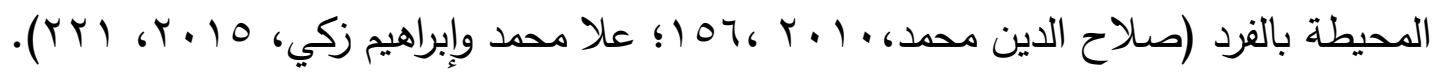
وتُعرف نوعية الحياة الأسرية بأنها العلاقات والممارسات الإيجابية التي يتبعها الوالدين

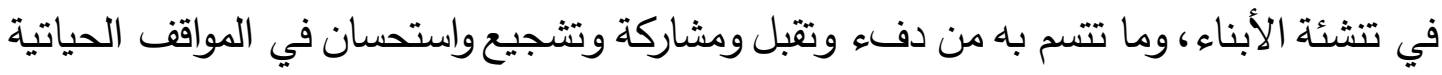

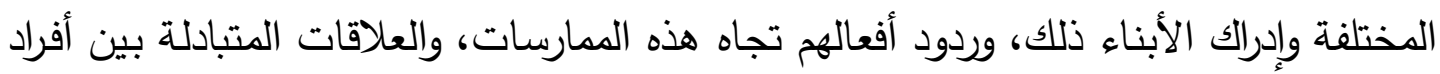
الأسرة، وما تتسم بـه هذه العلاقات من أساليب سوية في التعامل لتحقيق الأهداف، وإنجاز الإناه

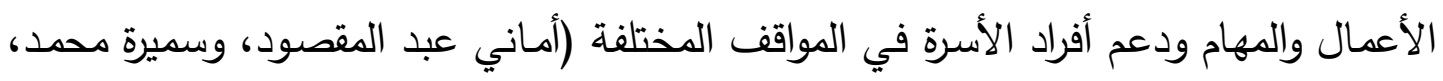

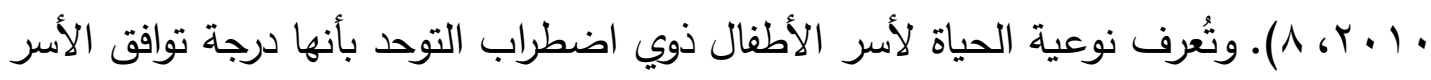

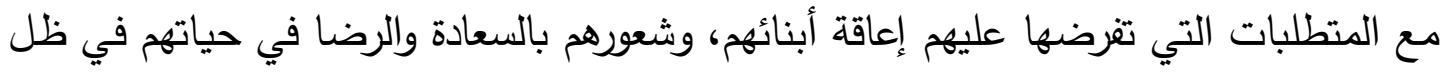

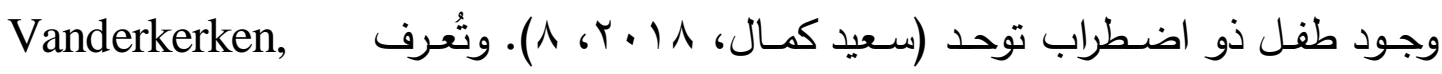
Heyvaert, Onghena, \& Maes, B. (2019)

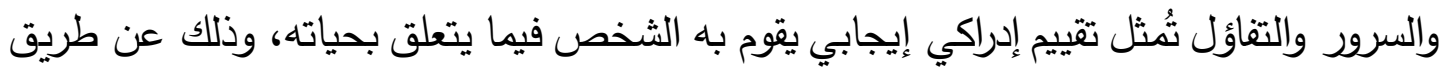

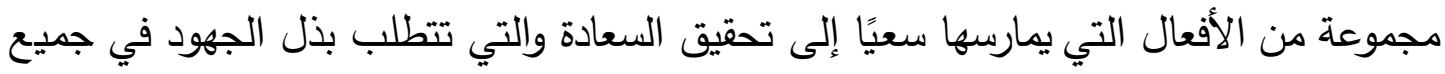

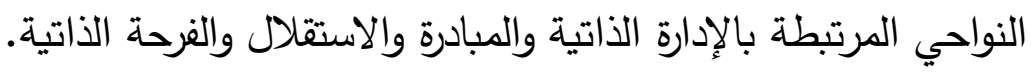
ورأي (2003) Poston et al., أن أبعاد نوعية الحياة الأسرية توزع على بعدين أساسين: البعد الأول يتمثل في الجوانب الثخصية مثل: السعادة الانفعالية، والبيئة المادية،

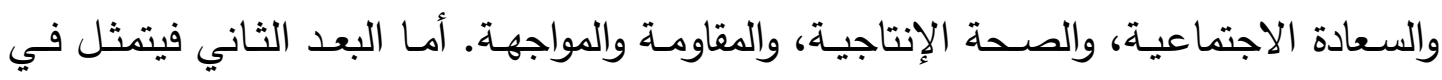
الجوانب الأسرية ممثلة في التفاعل الأسري، والحياة اليومية الوالدية، والحالة المادية المتيسرة. 
وتتمثل المؤشرات النفسية لنوعية الحياة الأسرية لدى أشقاء الأطفال ذوي اضطراب التوحد

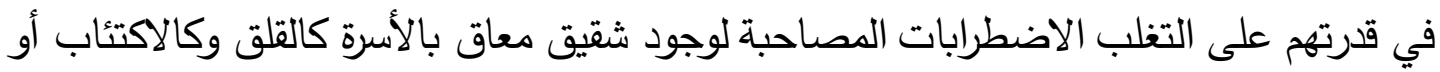

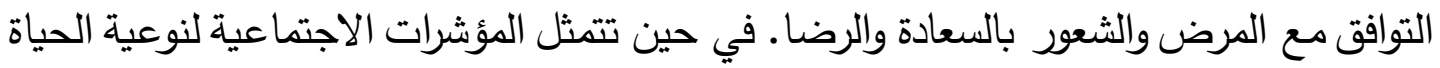
الأسرية لايهم في نجاح العلاقات الثخصية وممارستهم للأنثطة الاجتماعية.

\section{ج) العلاقة بين التوافق النفسي الاجتماعي ونوعية الحياة الأسرية لدى أشقاء الأطفال التوحديين}

لا شك أن الأشقاء العـاديين للأفراد ذوي الإعاقات يكونون عرضــة أكثر من غيرهم

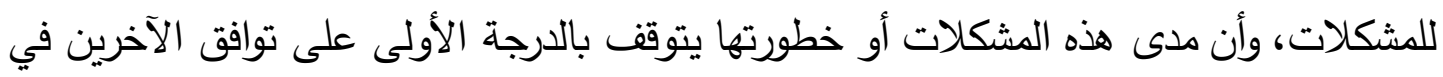

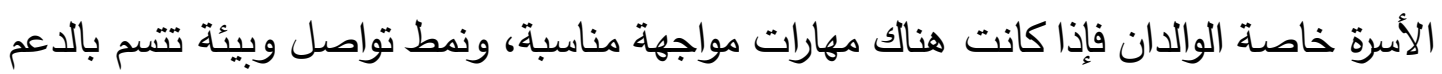
المتبادل فينتج عن ذلك التأثير الإيجابي نحو الأشقاء، فالعوامل الأسرية إذن تعتبر مؤشرًا هائًا

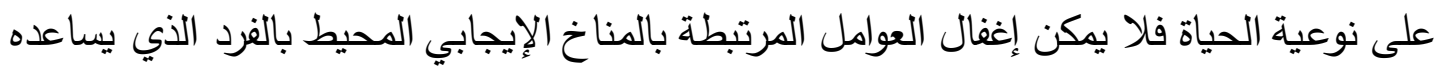
على تخطي مشكلاته النفسية والاجتماعية المختلفة (Walton, \& Ingersoll, 2015, 2771).

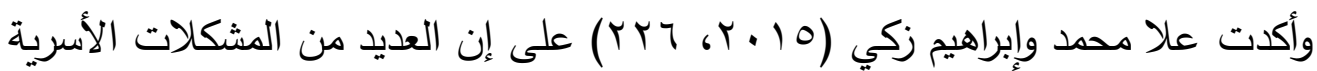

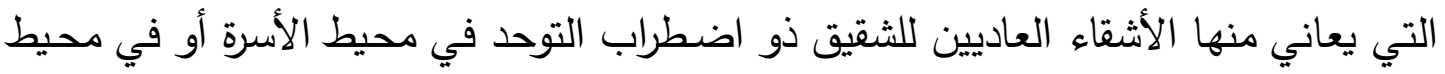
المجتمع الخارجي، هي مشكلات تُشكل لهم العديد من مصادر الضيق والإحباط، مما يؤثر في تكيفهم النفسي والاجتماعي، فإذا لم نتخخل بالبرامج التي تعمل على تحسين نوعية الحياة لديهم

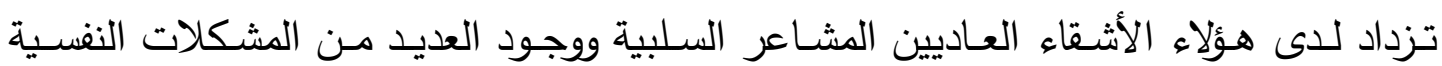
والاجتماعية التي لا يحمد عقباها فيما بعد.

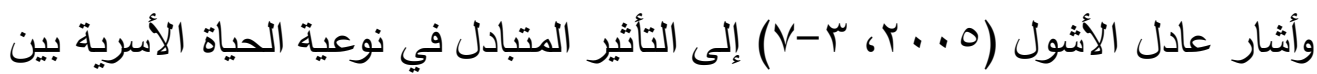

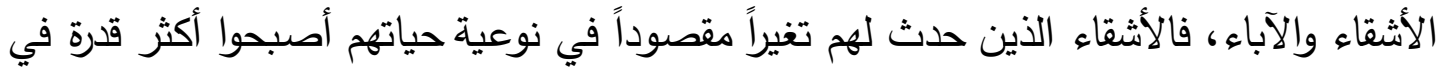
التوافق مع أشقائهم ذو الإعاقة، وذلك في حد ذاته يمكن أن يؤثر بالإيجاب على نوعية الحياة

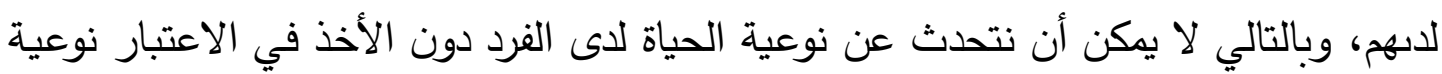
الحياة لاى من يحيطون فى دائرة تفاعلات هذا الفرد.

من هنا نستخلص أن وجود شخص ذو اضطراب توحد في الأسرة يؤثر تأثيرًا كبيرًا على نوعية حياة أشقائه، حيث يشعرون بالهموم والضغوط الحياتية مما يؤثر على الناحية الانفعالية 
والنفسية والاجتماعية، وبالتالي هم بحاجة إلى مساندة من المحيطين بهم لإدرالك معنى الحياة

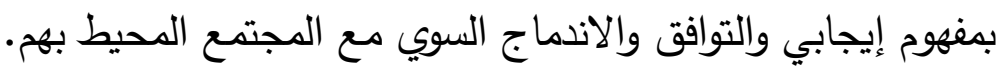

\section{دراســات سـابة سـة}

أ) دراسات سابقة مرتبطة بالتوافق النفسي الاجتماعي للدى أشقاء الأطفال ذوي اضطراب التوحد. هدفت دراسة (2012) معرفة مستوي التوافق النفسي لدى أثقاء

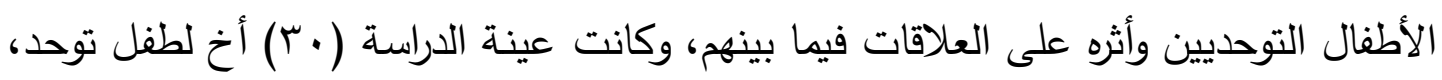
وترواحت أعمارهم من ( V-0 ) عامًا، طُبق عليهم مقياس التوافق النفسي، وتوصلت نتائج

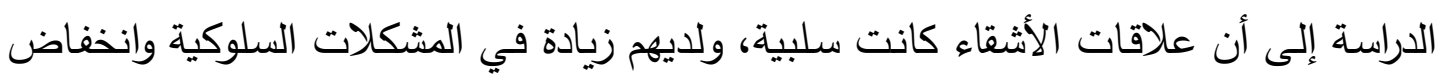
مشاعر الجو الأسري والدفء والنوعية الحياتية في حالة وجود شقيق يعاني من اضطراب التوحد.

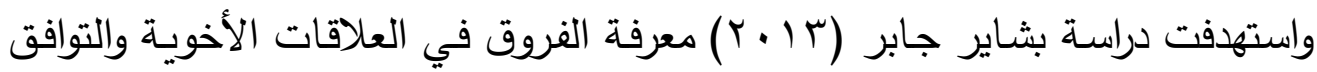
النفسي الاجتماعي لاى أشقاء الأطفال التوحديين ذوي الأداء الوظيفي المرتفع والمنخفض في الكويت، وتكونت عينة الدراسة من (Or) أخ واخت لطفل ذو اضطراب التوحد، تراوحت أعمارهم

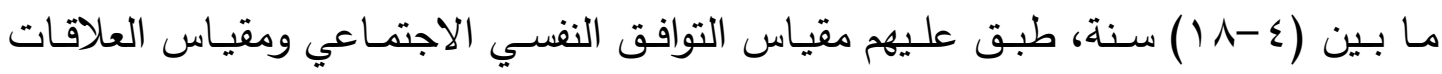

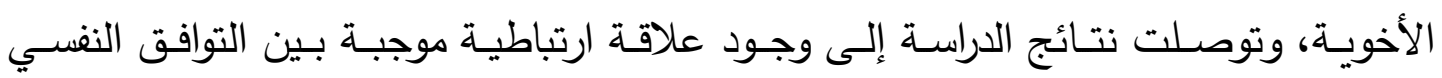

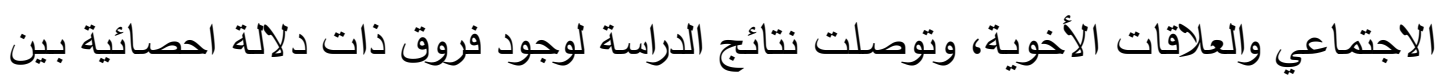

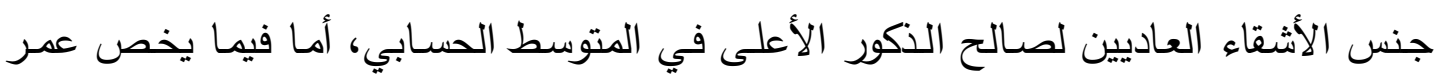
الأشقاء فلم توجد فروق بين الأشقاء الأصغر والأشقاء الأكبر في التوافق النفسي الاجتماعي. وحاولت دراسة Di Biasi et al., (2015) التعرف على مشكلات التوافق النفسي الاجتماعي لأشقاء الأطفال التوحديين، وكذلك معرفة تأثير (ترتيب الميلاد والنوع وعدد الأشقاء في الأسرة) على التوافق النفسي الاجتماعي لاى أشقاء الأطفال التوحديين، والذين بلغ عددهم (YT) شقيق، وتوصلت نتائج الدراسة إلى أن مستوي مشكلات التوافق النفسي الاجتماعي كان

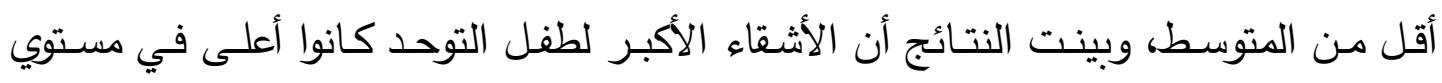
الضغوط النفسية وسوء التوافق النفسي الاجتماعي. 
وقارنت دراسة Walton, \& Ingersoll, (2015) بين التوافق النفسي الاجتماعي

والعلاقات بين أشقاء الأطفال التوحديين وأثقاء الأطفال العاديين، وتكونت عينة الدراسة من لهن

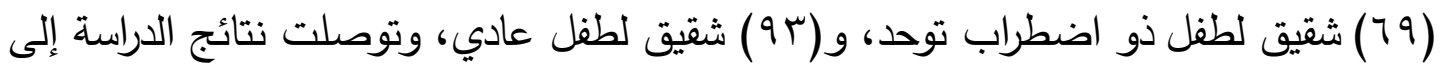

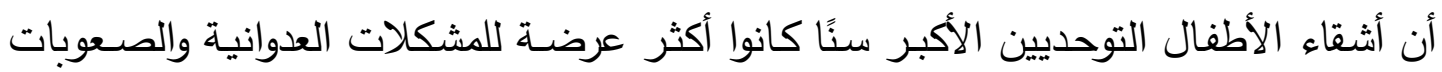
النفسية والاجتماعية، وكانوا أكثر عزلة وأقل مشاركة من أثقاء الأطفال العاديين.

وفعرفة مستوي التوافق هذا السياق هدفت دراسة (2016) Soseph, \& Kelly النفسي الاجتماعي لأشقاء الأطفال ذوي اضطراب التوحد في هونغ كونغ، وكانت العينة (1) (1)

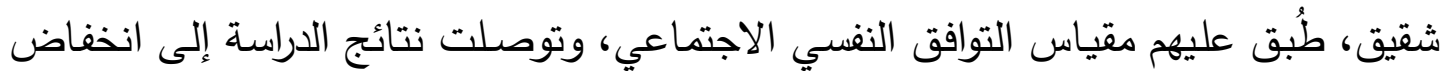

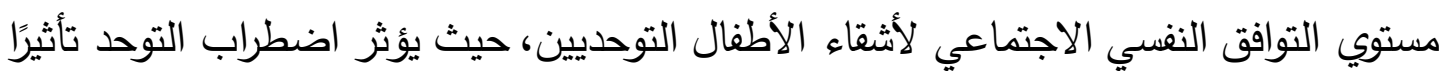

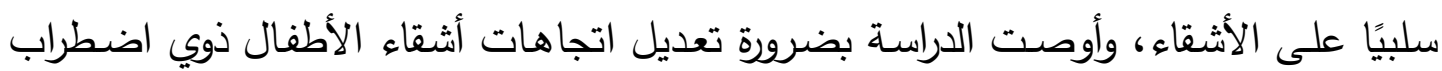

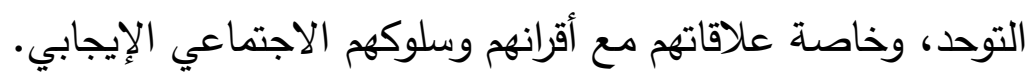
وهدفت دراسة Tsai, Cebula, \& Fletcher-Watson, (2016) إلى التعرف على التوافق النفسي الاجتماعي لأشقاء الأطفال ذوي اضطراب التوحد في ضوه ضواء بعض المتغيرات

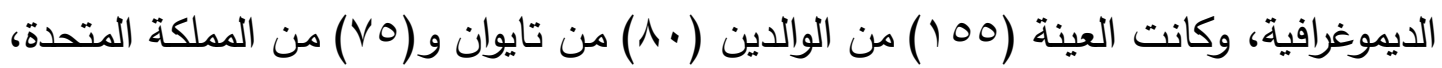

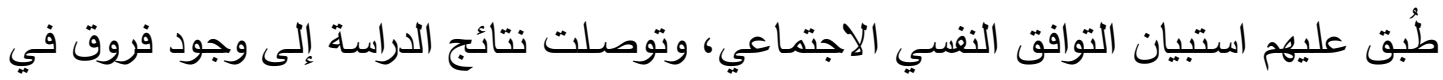

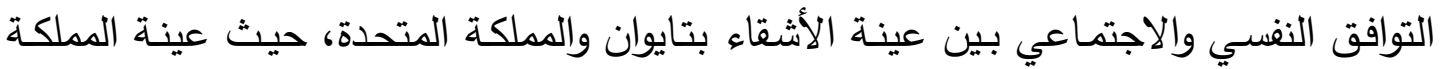
المتحدة لديهم استقرار وتوافق نفسي واجتماعي، بينما عينة تايوان لديهم صعوبات كبيرة في بي التوافق، وتوصلت النتائج إلى أن أسلوب تعامل الوالدين مع مشكلات الأشقاء ساهم بشكل كبئه

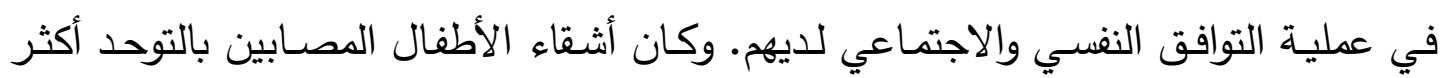
عرضة للإصابة بمشكلات عاطفية وسلوكية مقارنة بأشقاء الأطفال العاديين. واستهدفت دراسة محمد عبد القادر(Y V • Y) إلى التعرف على العلاقة بين المشكلات السلوكية الثائعة لاى أشقاء الأطفال ذوي اضطراب التوحد وبين حاجاتهم النفسية، وتكونت

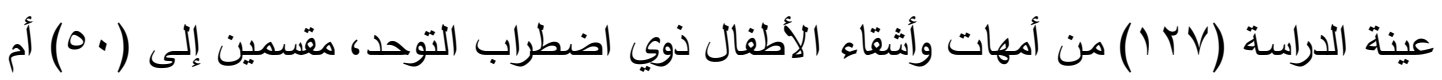

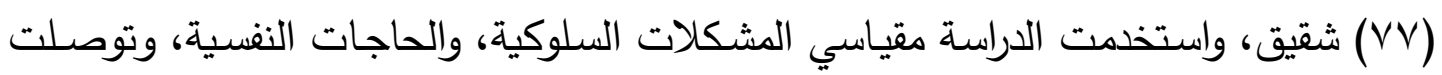
الدراسة إلى وجود علاقة ارتباطية سالبة بين الشككلات السلوكية (عدا سوء التوافق الدراسي) 
والحاجات النفسية لدى عينة الدراسة، كذلك وجد تأثير دال إحصائيًا لمتغيرى النوع والعهر الزمنـي والتفاعل بيزهمـا على الحاجـات النفسـية، كمـا خلصـت الدراسـة إلى إمكانيـة التنبؤ بالمشكلات من خلال الحاجة للأمن.

وهدفت دراسة Tudor, Rankin, \& Lerner, (2018) إلى معرفة آثر نموذج الأداء الأسري لدى أشقاء الأطفال ذوي اضطراب التوحد على توافقهم النفسي والاجتماعي، وكانت

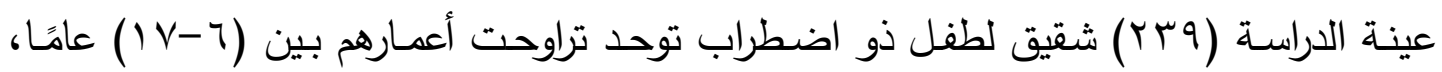

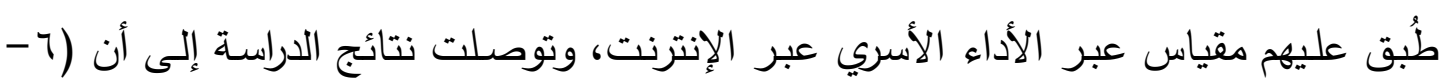

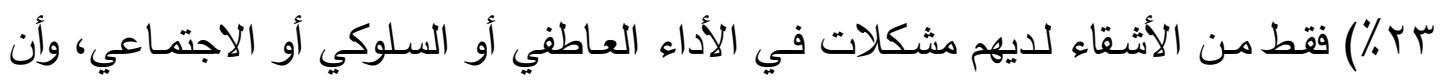
درجة اكتئاب الأم تؤثر في توقع أداء الأشقاء في علاقاتهم ببعضهم.

Cebula, Gillooly, Coulthard, Riby, \& Hastings, (2019) أما دراسة

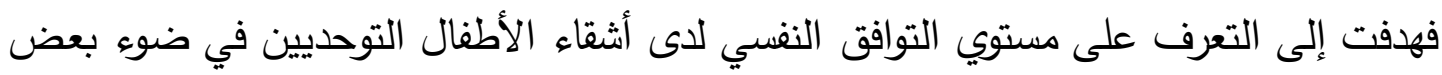

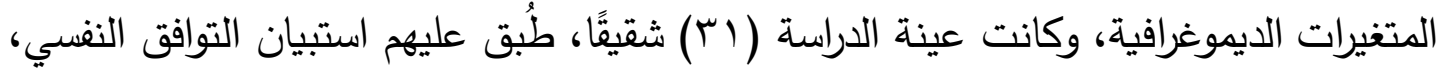

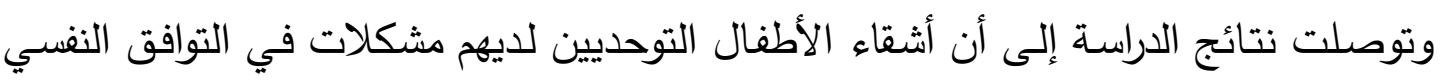
بالإضافة إلى مشكلات عاطفية وسلوكية متعدة.

\section{ب) دراسات سابقة مرتبطة بنوعية الحياة الأسرية لدى أشقاء الأطفال ذوي اضطراب التوحد}

هدفت دراسة (2011) معرفة نوعية الحياة الأسرية لدى

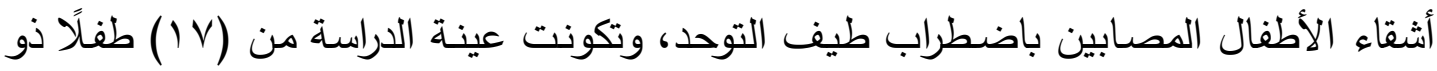
اضطراب التوحد وأشقائهم، ترواحت أعمارهم بين ه-17 17 عامًا، وأشارت النتائج إلى أن أشقاء أنقاء

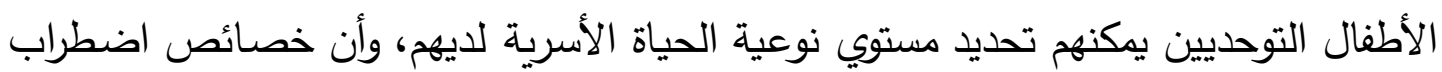

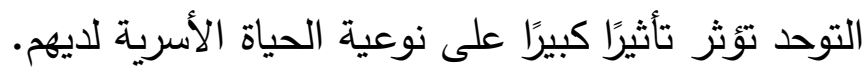

أما دراسة (2013) Meral et al., فهدفت إلى الكثف عن تصورات نوعية الحياة الأسرية والعلاقات التنبؤية المرتبطة بها لدى مجموعة من أُسر الأطفال التوحديين، وكانت عينة

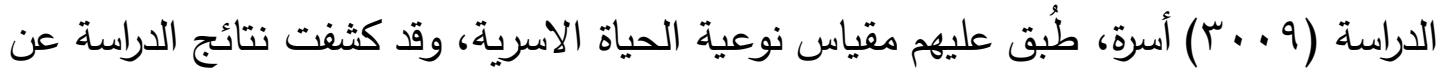

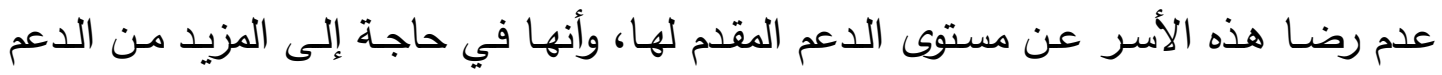


والخدمات الإرشادية لمساعدتها على التخفيف من الآثار السلبية لوجود أطفال معاقين فيها، وتحسين نوعية الحياة الأسرية لديها.

وهدفت دراسة Tomeny, Ellis, Rankin, \& Barry, (2017) إلى معرفة العلاقة

نوعية الحياة والجوانب النفسية لاى أشقاء الأطفال ذوي اضطراب التوحد، وكانت العينة (rی) شقيق لطفل ذو اضطراب التوحد، طُبق عليهم استبيان نوعية الحياة الأسرية، وتوصلت نتائج الدراسة إلى أن أشقاء الأطفال ذوي اضطراب التوحد لديهم مستويات أقل في نوعية الحياة الأسرية، ويرتبطون سلبًا بمستويات التوتر والاكتئاب.

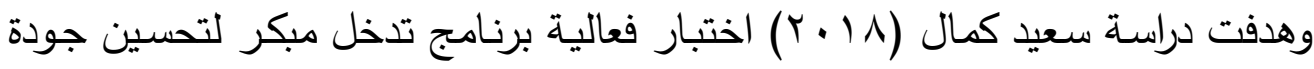

الحياة لأُسر الأطفال التوحديين وأثره على الوعي الذاتي لأطفالهم في عمر ما قبل المدرسة، وكانت العينة (^) أطفال ذوي اضطراب التوحد برياض الأطفال، أعمارهم بين (^ء - Vآ)

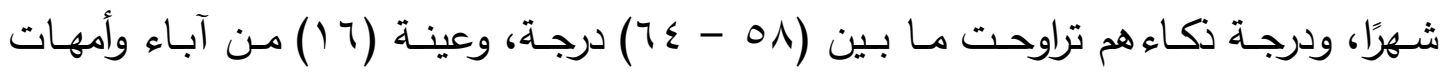

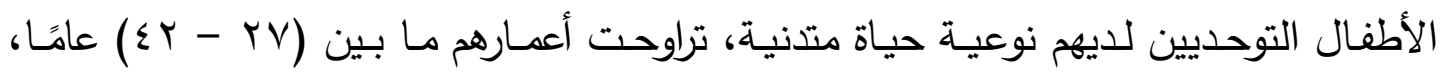
واستخدت الدراسة مقياسي نوعية الحياة والوعي الذاتي وبرنامج التنخل المبكر، وأسفرت نتائج الدراسة عن تحسين نوعية الحياة لأسر الأطفال التوحديين، وتحسين الوعي الذاتي لأطفالهه، واستمر الأثر الإيجابي للبرنامج على المجموعة التجريبية خلال فترة المتابعة. وهدفت دراسة عيد جلال، وسجي عبدالله (9 ب ب) الكثف عن فاعلية برنامج إرشادي لتحسين جودة الحياة لأسر الأطفال ذوي الاحتياجات الخاصة، وبلغت عينة الدراسة (r أ) أسرة، واستخدمت الدراسة مقياس نوعية الحياة الأسرية، وبرنامج إرشادي لتحسين نوعية الحياة الأسرية، وتوصلت النتائج لوجود فروق بين القياس القبلي والبعدي للمجموعة التجريبية لصالح القياس البعدي، كما أظهرت النتائج عدم وجود فروق بين القياس القبلي والبعدي في المجموعة والضابطة، ووجود فروق بين القياس البعدي في الهجموعة الضابطة والقياس البعدي في المجموعة التجريبية. 
ج) دراسات سابقة ربطت بـين التوافق النفسي الاجتماعي ونوعيـة الحياة الأسرية للدى أشقاء الأطفال ذوي اضطراب التوحل

استكشفت دراسة Fullerton, Totsika, Hain, \& Hastings, (2016 العلاقة بين

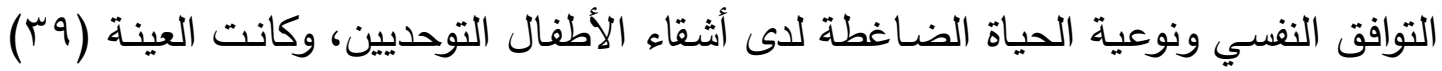
شقيقًا تتراوح أعمارهم بين (ץ-7 (1) سنة، طبق عليهم مقياسي الصعوبات العاطفية والسلوكية

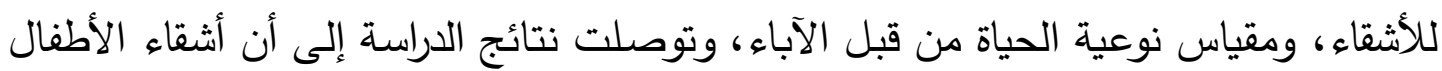

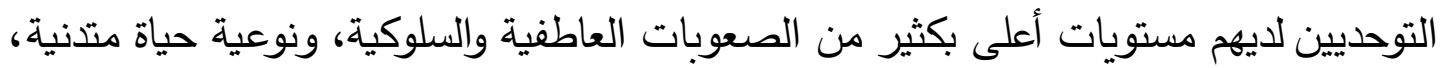

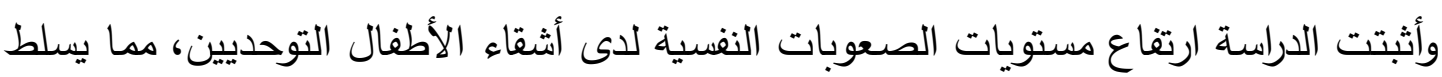
الضوء على الحاجة إلى تقديم الدعم لهؤلاء الأشقاء وأسرهم.

وهدفت دراسة Eyuboglu, Baykara, \& Eyuboglu, (2017) إلى إجراء مقارنة بين أشقاء الأطفال ذوي اضطراب التوحد والأطفال العاديين في بعض الخصائص الاجتماعيـة

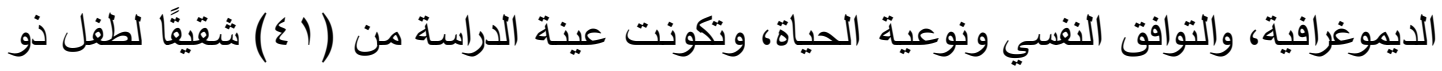

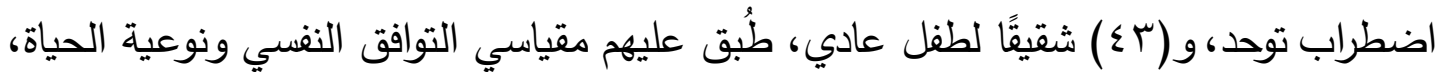

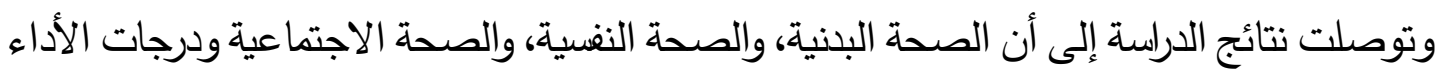

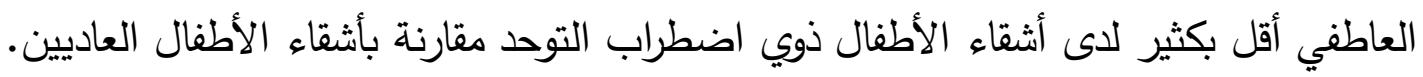

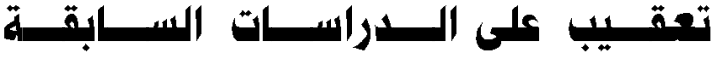

اتضـح من مراجعة الدراسـات السـابقة أنها جمعيها أُجريت على أشقاء الأطفال ذوي اضطراب التوحد، باختلاف الأعمار والظروف المكانية، وأمكن ذلك إلى عدة استتناجات وهي: 1 - معظم الدراسات احتوت على عينات صغيرة نسبيًا تراوحت من (Y I) إلى (Y) مشاركًا

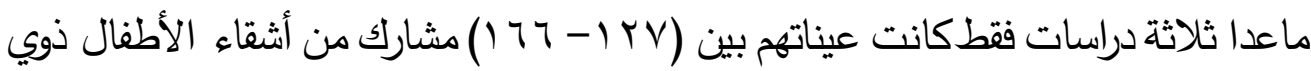

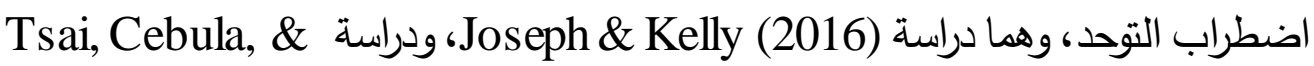

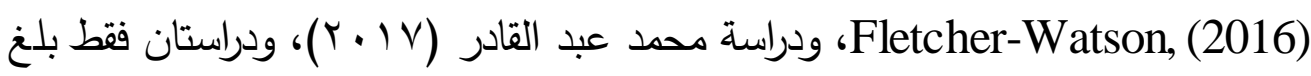

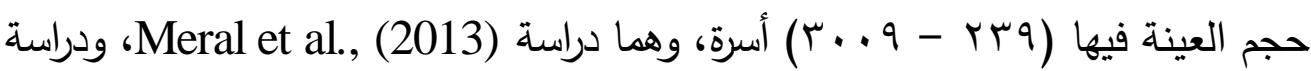
Tudor, Rankin, \& Lerner, (2018) مما يجعل الدراسة الحالية تتسم بالتقرد عن الدراسات السابقة حيث شارك فيها (1) (1) من أشقاء الأطفال ذوي اضطراب التوحد. 
r-تباينت المقاييس المستخدمة لتقييم التوافق النفسي الاجتماعي ونوعية الحياة الأسرية

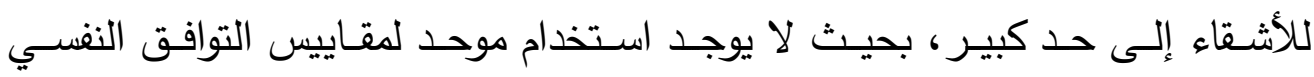

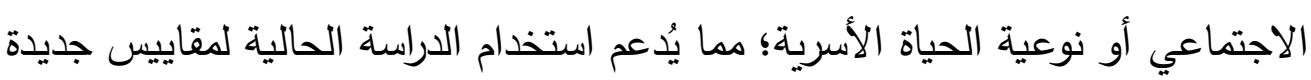
للتوافق النفسي الاجتماعي ونوعية الحياة الأسرية تتناسب وطبيعة عينة الدراسة.

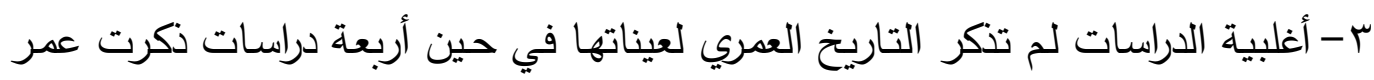

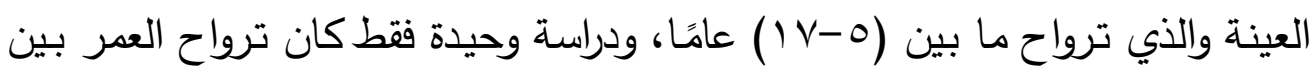

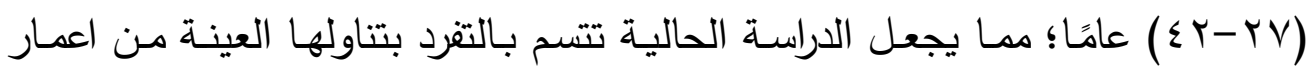

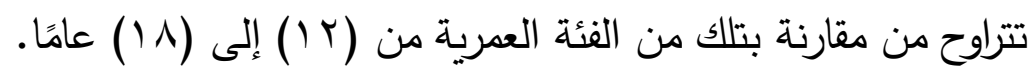
ـ - نتائج الدراسات السـابقة متناقضـة فيما يتعلق بتأثير نوع الأشقاء، والعمر في عمليـة

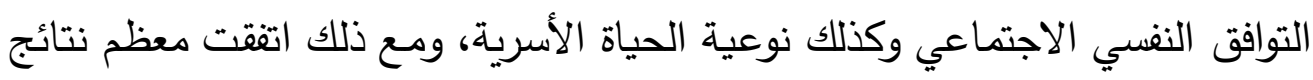

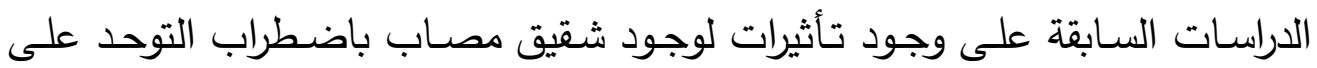
أشقائه في نفس الأسرة. 0-ندرة الدراسات العربية - في حدود علم الباحث- التي اهتمت بدراسة العلاقة بين

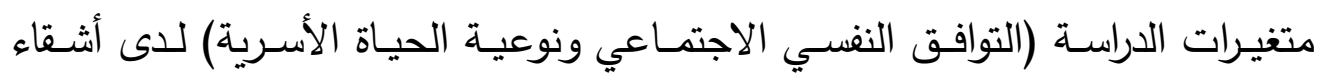
الأطفال ذوي اضطراب التوحد.

\section{فـروض الــدراســة}

1-توجد مستويات متوسطة لكل من (التوافق الثخصي، والتوافق الاجتماعي) لاى أشقاء

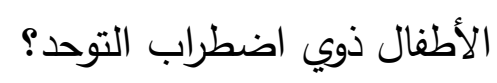

r-توجد علاقة ارتباطيـه دالة إحصـائيًا بـين درجـات عينـة الدراسـة في التوافق النفسي الاجتماعي ودرجاتهم في نوعية الحياة الأسرية.

ب-توجد فروق دالـة إحصـائيًا بين متوسطات درجات عينـة الدراسـة في التوافق النفسي

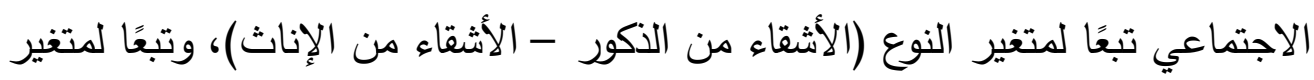

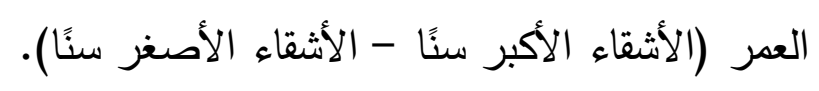


ـ - توجد فروق دالة إحصائيًا بين متوسطات درجات عينة الدراسة في نوعية الحياة الأسرية

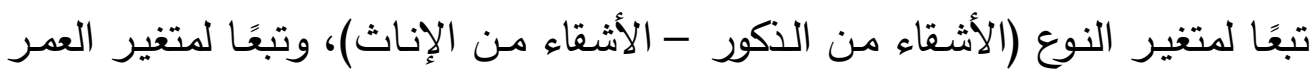
(الأشقاء الأكبر سنًا - الأثقاء الأصغر سنًا). ه- يُسهم التوافق النفي الاجتماعي في التبؤ بنوعية الحياة الأسرية لاى أثقاء الأطفال التوحديين.

\section{محسدةات الـدراسـة}

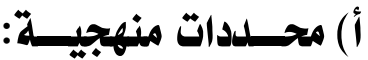

استخدمت الدراسة المنهج الوصفي الذي يهدف إلى دراسة الظروف والعلاقات وتحليلها وتفسير ها لاستخلاص دلالاتها، وباعتبار هذه الدراسة سيكومترية تهدف إلي التعرف علي التوافق

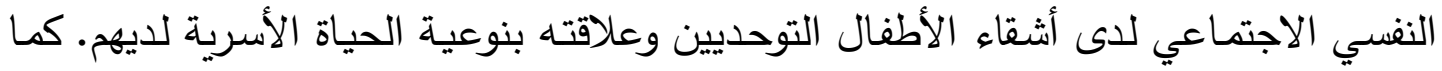

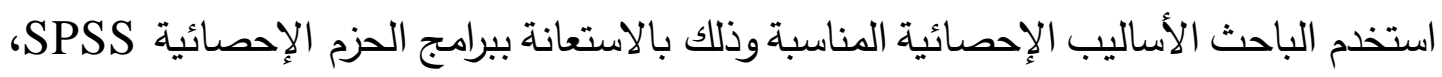
ومنها: معامل ارتباط بيرسون، واختبار ت (T-TEST)، وتحليل الانحدار البسيط.

\section{ب) محسـدات العينـــة}

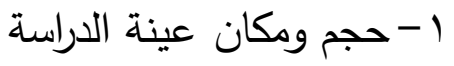

بلغ إجمالي حجم العينة الكلية للدراسة (14 ( ) من أثقاء الأطفال ذوي اضطراب التوحد ووصفهم كالآتي:

عينة استطلاعية: تكونت من (70)من أشقاء الأطفال التوحديين، تم الحصول على بياناتهم والتواصل معهم من قبل بعض من مراكز التربية الخاصة بمحافظة بني سويف المتابعة لحالة أشقائهم ذوي اضطراب التوحد، ولذلك للتأكد من الكفاءة السيكومترية لأدوات الدراسة وتم استبعاد

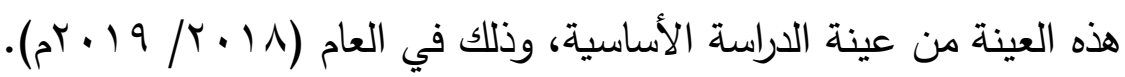

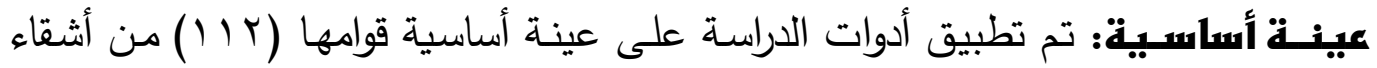
الأطفال التوحديين، من نفس أماكن العينة الاستطلاعية، حيث بلغ عدد من الأشقاء الذكور

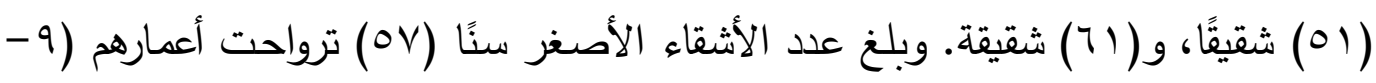

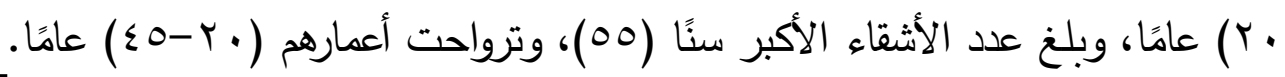




\section{ج) أدوات الــلدراســة}

استخدمت الاراسة الأدوات التالية:

1-مقياس التوافق النفسي الاجتماعي لدى أشقاء الأطفال التوحديين (إعداد الباحث).

r-مقياس نوعية الحياة الأسرية لاى أثقاء الأطفال التوحديين (إعداد الباحث).

ويعرض الباحث فيما يلي عرضًا وصفيًا لهذه الأدوات التي قام بإعدادها أو تصميمها

لهلف الدراسة وما اتبعه من إجراءات للتحقق من صدقها وثباتها.

ا- مقياس التوافق النفسي الاجتماعي لدى أشقاء الأطفال التوحلييز (إعداد الباحث).

لقد قام الباحث ببنـاء مقياس التوافق النفسي الاجتمـاعي بعد الإطـلاع على الأُطر

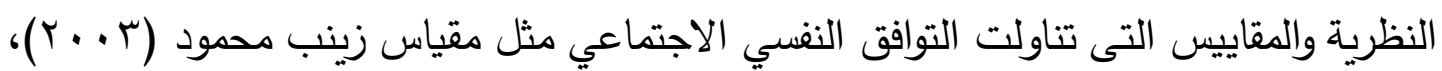

ومقياس (2016) Tsai, Cebula, \& Fletcher-Watson, ومقياس صفاء عبد الزهرة

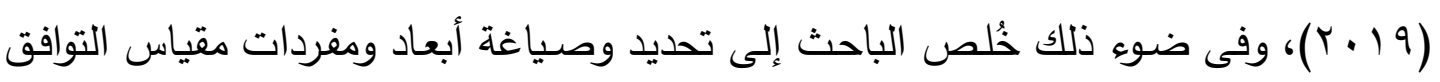
النفسي الاجتماعي لاى أشقاء الأطفال التوحديين.

\section{أبعاد المقياسر : انقسم المقياسر إلى بـعدين أساسين وهُما:} البعد الأول: التوافق النفسي:

ويُعرفه الباحث إجرائياً بأنه: "عملية ديناميكية تظهر في مدي رضا الفرد عن نفسه وذاته، وفيه تكون حاجات الفرد مشبعة تمامًا، وخلو الفرد من الاضطرابات النفسية والعصبية، وتمتعها

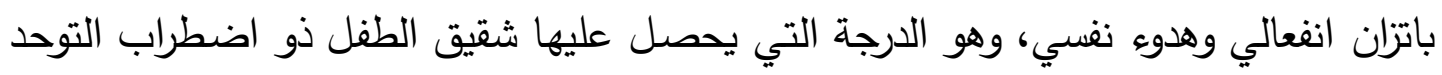

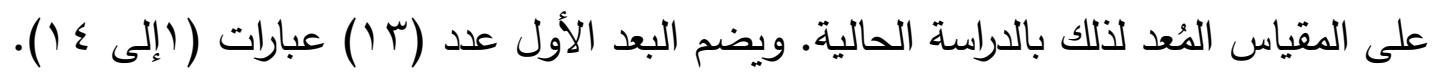
البعد الثاني: التوافق الاجتماعي:

ويُعرفه الباحث إجرائياً بأنه: "عملية ديناميكية تظهر في مدي رضا الفرد عن الآخرين، وإقامته علاقات اجتماعية ناجحة تتسم بالاستمراريه، وامتثاله لقواعد الضبط الاجتماعي، وهو الدرجة التي يحصل عليها شقيق الطفل ذو اضطراب التوحد على المقياس المُعد لذلك بالدراسة

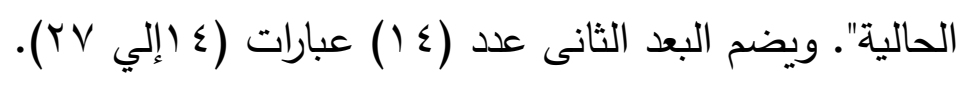


تكون هذا المقياس من (YV) عبارة، تمت الإستجابة عليها من خلال اختيار إجابة

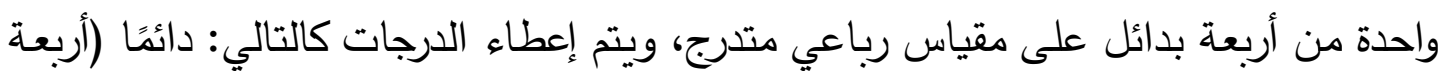

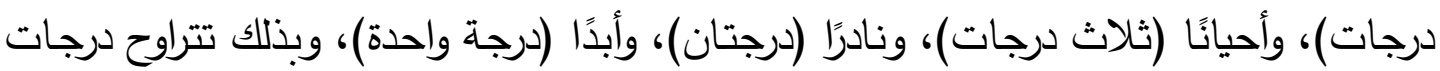

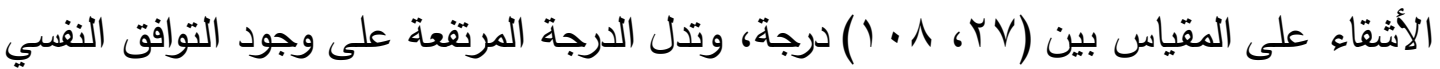

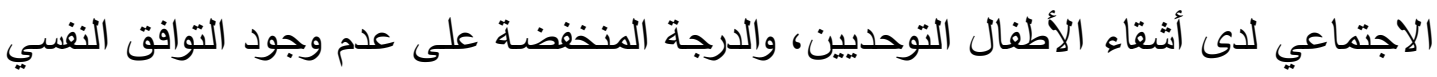
الاجتماعي للى أشقاء الأطفال التوحديين.

التحقق من الكفاءة السيكومترية لمقياس التوافق النفسي الاجتمـاعي للى أشقاء

الأطفال التوحديين

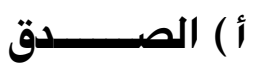

• صدق المكمين: تََّّ عرض المقياس في صورته الأولية على عدد من أساتذة التربية الخاصة

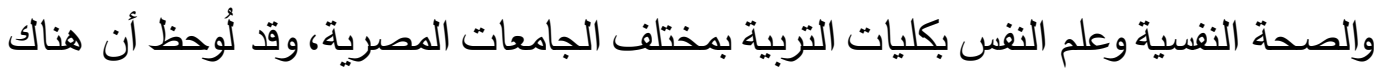
عدد كبير من المفردات يحظى بنسبة اتفاق المحكين ( . . ( ٪) وهناك مفردات حظيت بنسبة اتفاق (• ٪\%) ومفردات أخري كانت نسبة اتفاقها ( •^٪) ولم يتم حذف مفردة من المقياس. • صدق المكك: تم إيجاد صدق المحك من خلال إيجاد معامل الارتباط بين هذ المقياس ومقياس

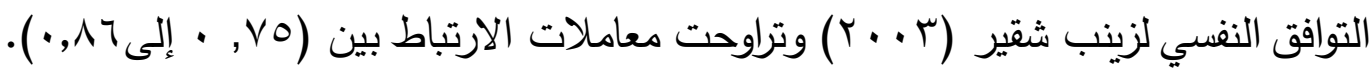

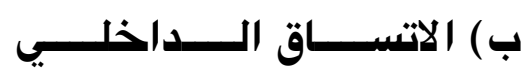

تم إيجاد التجانس الداخلي للمقياس عن طريق حساب معامل الارتباط بين درجات كل

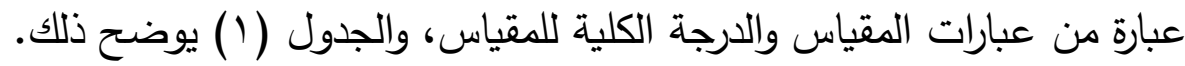

\begin{tabular}{|c|c|c|c|c|c|c|c|c|c|}
\hline معامل ارتباطها & مر D & معامل ارتباطها & مـ D & معامل ارتباطها & مـ & معامل ارتباطها & مـ D D & معامل ارتباطها & |لمثردة |لمرة| \\
\hline **•,VRV & ro & $* * \bullet, V \bullet \bullet$ & 19 & $* * \bullet, 07$ & ir & $* * \bullet, 7 \cdot 1$ & v & **•,Orr & 1 \\
\hline$* * \bullet, 0 Y r$ & $r y$ & $* * \bullet, Y r r$ & r. & $* * \bullet, 0 \leqslant 0$ & $1 \varepsilon$ & $* * \bullet, \neg \neg r$ & $\wedge$ & ***, OrA & $r$ \\
\hline \multirow[t]{4}{*}{$* * \bullet, 7 r r$} & rV & $* * \bullet, O V Y$ & r & $* * \bullet, 01 Y$ & 10 & $* * \bullet, \bigvee \wedge \varepsilon$ & 9 & **•, Irr & $r$ \\
\hline & & $* * \bullet, 001$ & rr & **•, ๆะ• & 17 & $* * \bullet, 00 r$ & 1. & $* * \bullet, Y Y Y$ & $\xi$ \\
\hline & & $* * \bullet, 71$ • & rr & ***,OYZ & iv & $* * \bullet, 7 \wedge 1$ & 11 & $* * \bullet, 0 \wedge 9$ & 0 \\
\hline & & $*^{* *}, \mathrm{~V} \backslash \mathrm{Y}$ & 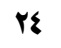 & $* * \bullet, V \leqslant \Lambda$ & 11 & $* * \bullet, 07 r$ & ir & **•, I Y & 7 \\
\hline
\end{tabular}

( معامل الارتباط دال إحصائياً عذ مستوى (1, *.) * 
ويتضـح من جدول (1) أن معـاملات الارتبـاط بـين درجـة كل مفـردة والدرجـة الكليـة للمقياس دالة إحصائيًا عند مستوى (1 +, •)، وهذا يدل على اتساق البناء الداخلي. تم إيجاد التجانس الداخلي للمقياس عن طريق حساب معامل الارتباط بين درجات كل بعد من أبعاد المقياس والدرجة الكلية للمقياس، حيث بلـغ معامل الارتباط لبعد التوافق

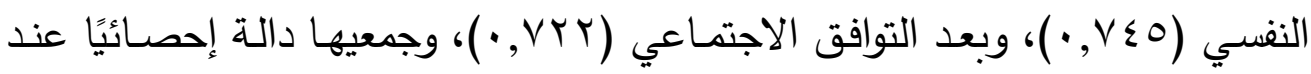

$$
\text { ج) ثبـــــات المقيــــــاس (1 مست. }
$$

الثبات بطريقة ألفا -كرونباخ، وطريقة إعادة تطبيق المقياس: تم حساب ثبات المقياس باستخدام طريقة ألفا - كرونباخ علي عينة استطلاعية مكونة من (70) شقيقًا، وقد تم

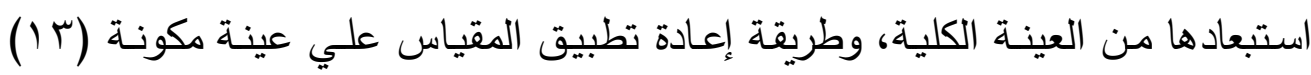

\begin{tabular}{|c|c|c|c|}
\hline إعادة التطبيق & معامل ثبات ألفا كرونباخ & عدد العبارات & الأبعـــــــاد \\
\hline$\cdot, \wedge \leqslant q$ & $\cdot, \wedge 07$ & ir & التواقق النفسي \\
\hline$\cdot$, Y07 & $\bullet, \vee \uparrow$ & $1 \varepsilon$ & التواقق الاجتماعي \\
\hline$\bullet, \wedge 9 \bullet$ & •,Аव & rr & الدرجة الكلية للمقياس \\
\hline
\end{tabular}
بفاصل زمني قدره أسبوعين بين التطبيقين الأول والثاني، والجدول (r) يوضح ذلك.

يتضح من الجدول(r) أن جميع قيم معاملات الثبات دالة إحصائيًا عند مستوى دلالة (1 ( , ·)، مما يجعلنا نثق فى ثبات المقياس.

الثبات بطريقـة التجزئـة النصفية: تم حسـاب معامل الثبات بطريقـة التجزئة النصفية ومعادلة سبيرمان براون، وطريقة جتمان، والجدول (ب) يوضتح ذلك.

\begin{tabular}{|c|c|c|}
\hline طريقة جتمان & طريقة سبيرمان براون & الأبعـاد \\
\hline •, $\vee 97$ & $\cdot, \wedge \wedge$. & التوافق النفسي \\
\hline$\cdot, \Lambda \mid \varepsilon$ & $\cdot, A Y I$ & التوافق الاجتماعي \\
\hline •,§97 & •, orr & اللدرجة الكلية للمقياس \\
\hline
\end{tabular}
جدول (r) معاملات الثبات بطريقة التجزئة النصفية (سبيرمان براوذ -وجتمان) 
يتضـح من الجدول (r) أن معامل الثبات بطريقة التجزئة النصفية بطريقة سبيرمان براون هو معامل ثبات مرتفع، كما أن معامل الثبات باستخدام معادلة جتمان هو معامل ثبات

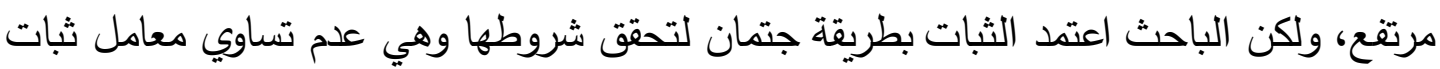

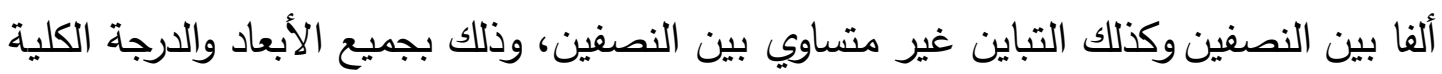

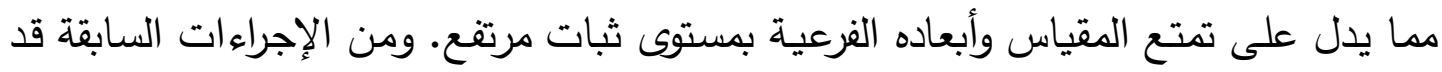

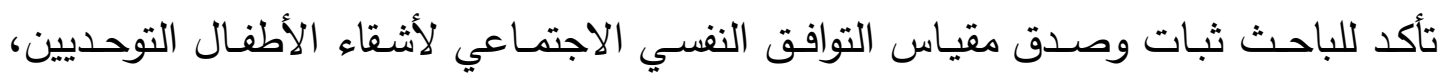
وصلاحيته للاستخدام في الدراسة الحالي.

\section{r- مقياس نوعية الحياة الأسرية للدى أشقاء الأطفال ذوي اضطراب التوحل}

قام الباحث ببناء مقياس نوعيـة الحياة الأسرية بعد الإطـلاع على الأُطر النظريـة

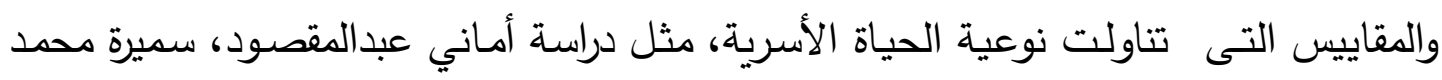

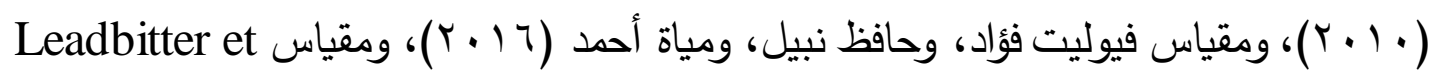

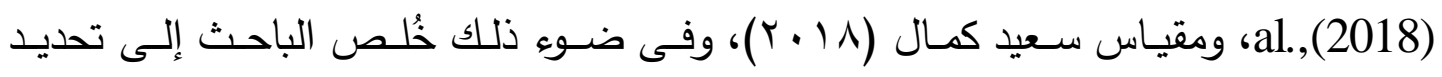
وصياغة مفردات مقياس نوعية الحياة الأسرية لاى أثقاء الأطفال التوحديين.

\section{طـريقــة تصميـح المقيــاسر:}

تكون هذا المقياس من (•r) عبارة، وتتم الإجابة على المقياس من خلال اختيار إجابة

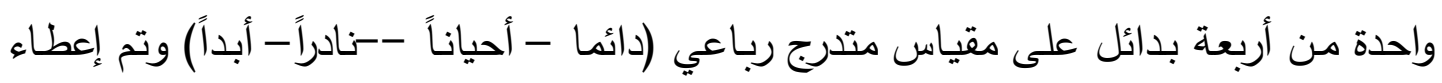

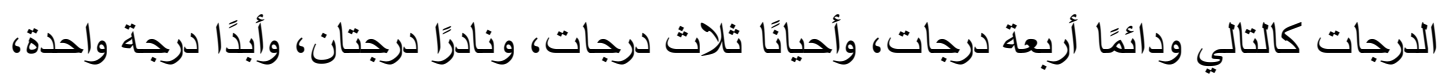

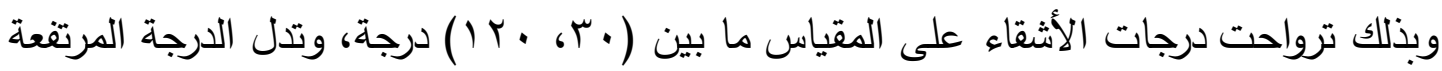

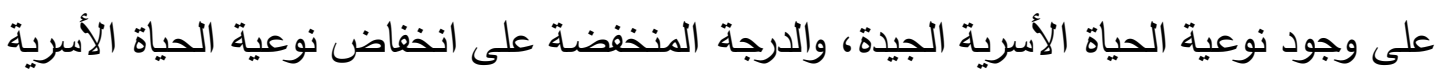
لاى أشقاء الأطفال التوحديين.

التحقـق مسن الكفـاءة السـيكومترية لمقيـاس نوعيـة الحيـاة الأسـرية لـدى أشـقاء الأطفال التوحديين 1- الصدق: اعتمد الباحث في قياس صدق المقياس على طريقتين وهما: • • صدق المحكمين: تنَّ عرض المقياس في صورته الأولية على عدد من أساتذة التربية الخاصـة والصحة النفسية وعلم النفس بكليات التربية بمختلف الجامعات المصرية، وقد 
لُوحظ أن هناك عدد كبير من المفردات يحظى بنسبة اتفاق المحكمين ( . . 1 \%) وهناك مفردات حظيت بنسبة اتفاق ( • ٪\%) ومفردات أخري كانت نسبة اتفاقها ( •^\%) ولم يتت حذف مفردة من المقياس.

• صدق المحك: تم إيجاد صدق المحك من خلال إيجاد معامل الارتباط بين هذا المقياس

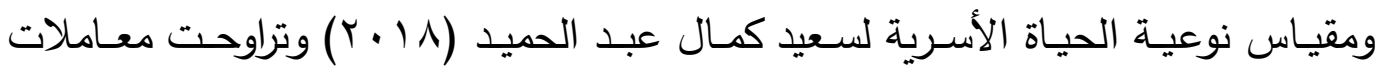

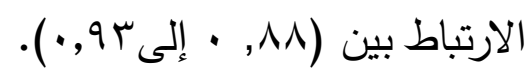

ץ- الاتسـاق الـداخلي: تم إيجاد التجانس الداخلي للمقياس عن طريق حساب معامل الارتباط بين درجات كل عبارة من عبارات المقياس والدرجة الكلية للمقياس، والجدول

$$
\text { ( ) يوضتح ذلك. }
$$

\begin{tabular}{|c|c|c|c|c|c|c|c|c|c|}
\hline معامل ارتباطها & 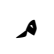 & معامل ارتباطها & 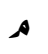 & معامل ارتباطها & هـ & معامل ارتباطها & 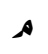 & معامل ارتباطها & | لمفردة \\
\hline$* * \bullet, Y \leqslant Y$ & ro & $* * \bullet, Y \leqslant 1$ & 19 & $* * \bullet, 097$ & it & $* * \bullet, \wedge \leqslant 0$ & $r$ & $* * \bullet, V \leqslant Y$ & 1 \\
\hline$* * \bullet, Y r V$ & rq & $* * \bullet, 790$ & r. & $* * \bullet, \wedge Y Y$ & 18 & $* * \bullet, \wedge 07$ & $\wedge$ & $* * \bullet, \vee \wedge \varepsilon$ & r \\
\hline **•, Var & YV & $* * \bullet, O \wedge Y$ & rI & $* * \bullet, \mathrm{V} \leqslant \Lambda$ & 10 & $* * \bullet, 719$ & 9 & $* * \bullet, \wedge \leqslant 0$ & $r$ \\
\hline$* *,, 790$ & rA & $* * \bullet, Y \leq Y$ & rr & $* * \bullet, 7 r \Lambda$ & 17 & $* * \bullet, \wedge \xi \bullet$ & 1. & $* * \bullet, \eta r \Lambda$ & $\varepsilon$ \\
\hline$* * \bullet, \vee \wedge \diamond$ & $r q$ & $* * \bullet, Y 0 \xi$ & rr & $* * \bullet, \vee \wedge \varepsilon$ & iv & $* * \bullet, V \leqslant 0$ & 11 & $* * \bullet, 790$ & 0 \\
\hline$* * \bullet, \wedge \leqslant r$ & r. & $* * \bullet, 791$ & Yz & $* * \bullet, 790$ & M & $* * \bullet, \wedge 07$ & ir & $* * \bullet, \vee \leqslant \Lambda$ & 7 \\
\hline
\end{tabular}

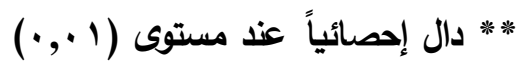

ويتضـح مـن جدول (ع) أن معاملات الارتبـاط بين درجـة كل مفردة والدرجـة الكليـة للمقياس دالة إحصائيًا عند مستوى (1 +, ·)، مما يدل على اتساق البناء الداخلي لمقياس نوعية الحياة الأسرية لاى أشقاء الأطفال التوحديين.

\section{ثبــــات المقيــاسـا}

الثبات بطريقة ألفا -كرونباخ، وطريقة إعادة تطبيق المقياس: تم حساب ثبات المقياس باستخدام طريقة ألفا كرونباخ علي عينة استطلاعية مكونة من (Tه) شقيقًا لطفل ذو اضطراب التوحد، وقد تم استبعادها من العينة الكلية، وبلغ معامل الثبات (דب^ر, )، 
وهي قيمة دالة إحصائيا عند مستوى دلالة ( ( , ·)، وتم حساب الثبات بطريقة إعادة التطبيق، علي عينة مكونة (T () شقيقًا، بفاصل زمني قدره أسبوعين بين التطبيقين الأول والثاني وبلغ معامل الثبات ( • (1, • )، وهي قيمة دالة إحصائيًا عند مستوى دلالة (1 ·, ·)، والجدول (ع) يوضح ذلك، مما يجعلنا نثق فى ثبات المقياس.

الثبات بطريقة التجزئة النصفية: تم حساب معامل الثبات بطريقة التجزئة النصفية وتطبيق

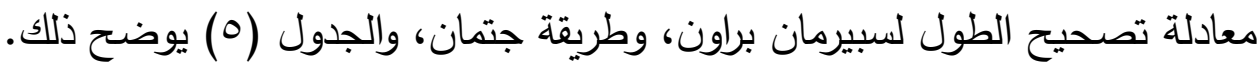

جدول (0) معاملات الثبات بطريقة التجزئة النصفية (سبيرمان براون -وجتمان)

\begin{tabular}{|c|c|c|}
\hline طريقة جتمان & طريقة سبيرمان براون & الأبعــــاد \\
\hline •, & $\cdot, \wedge \wedge$. & نوعية الحياة الاسرية \\
\hline
\end{tabular}

يتضـح من الجدول (0) أن معامل الثبات بطريقة التجزئة النصفية بطريقة سبيرمان براون وبمعادلة جتمان هو معامل ثبات مرتفع، ولكن الدراسة الحالية اعتمدت الثبات بطريقة

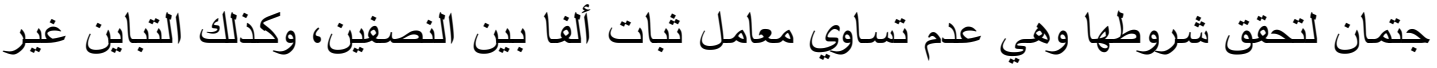

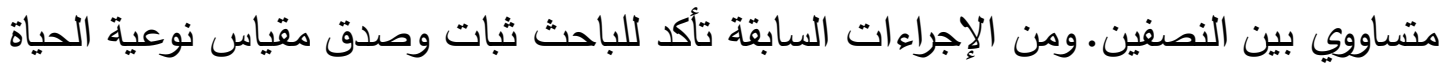
الأسرية لأشقاء الأطفال التوحديين، وصلاحيته للاستخدام في الدراسة الحالية.

\section{نتسائسج الـراسـة ومنساقشتهـا}

\section{نتائج فروض الدراسة ومناقشتها في ضوء الإطار النظري والدراسات السابقة.}

\section{نـتيجــة الفــرض ومنــاقشتهــا}

يـنص الفـرض الأول علـى "توجد مستويات متوسطة لكل من (التوافق الثخصسي،

$$
\text { والتوافق الاجتماعي) لاى أشقاء الأطفال ذوي اضطراب التوحد"؟ }
$$

للإجابـة على هذا الفرض، تم حساب المتوسطات الحسابية، والانحرافات المعياريـة لاستجابة أشقاء الأطفال التوحديين على مقياس التوافق النفسي الاجتماعي، ونظرًا لاختلاف

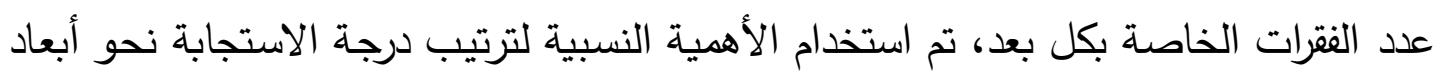
مقياس التوافق النفسي الاجتماعي، والجدول (†) يبين نتائج التحليل. 
التوافقة النفسي الاجتماعيا ونوعيةالحياة الأسرية لوىأشقاء الأطفال ذوي اضطراب التوحد

د. أحمد محمد عزازي

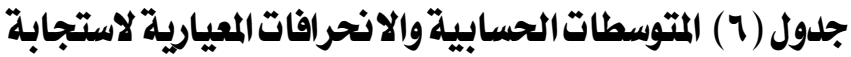

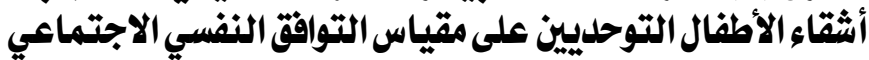

\begin{tabular}{|c|c|c|c|c|c|}
\hline الترتيب & الأهمية النسبية & الانحراف المعياري & المتوسط الحسابي & عدد الفقرات & أبعاد التواقق النفسي الاجتماعي \\
\hline 1 & $\% \wedge \varepsilon, \bullet 0$ & 0,1 & $\{r, r)$ & ir & التوافق النفسي \\
\hline r & $\%$ vo, ro & $v, \xi T$ & \&r, r. & $1 \xi$ & التواقق الاجتهاعي \\
\hline \multicolumn{2}{|r|}{$\%$ vq,or } & $1 \cdot, \cdot r$ & $\wedge \bullet, ৭$. & rr & اللرجة الكلية \\
\hline
\end{tabular}

يتضح من جدول (†) أن استجابات أشقاء الأطفال التوحديين كانت نحو بعد التوافق

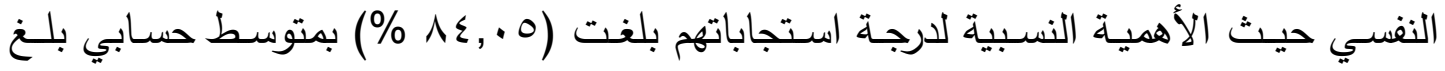

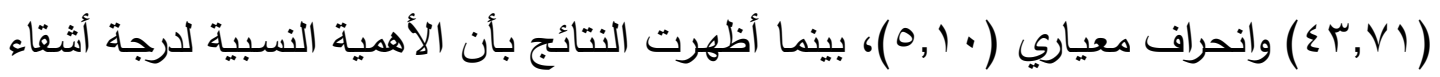

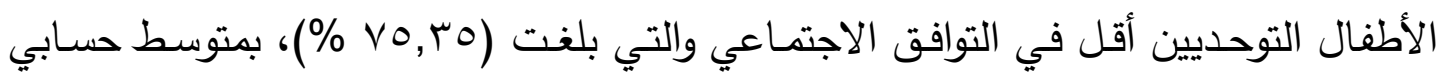

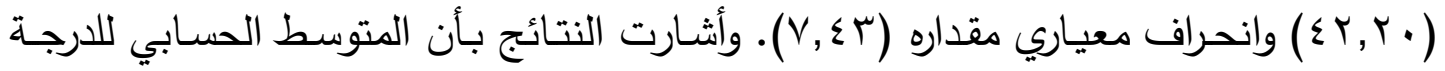

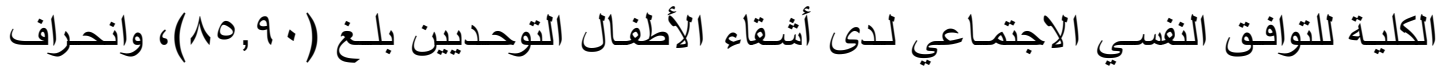

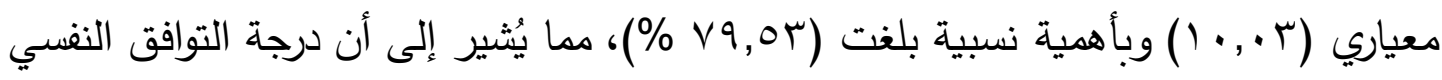
الكلي لاى أثقاء الأطفال التوحديين متوسطة. ويرجع الباحث ذلك إلى وجود مشكلات تكيفية

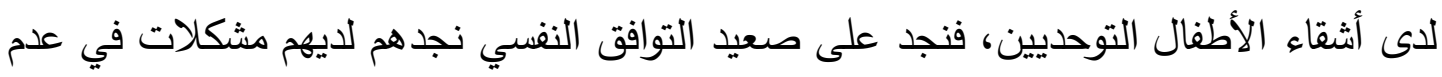
القدرة على إشباع الحاجات والميول النفسية والتي تتمثل في عدم تقبلهم لذواتهم، وعدم ثقتهم بقدراتهم وإمكانياتهم، وصعوبة التوزان الإنفعالي وخاصة في المواقف الضاغطة؛ مما يؤثر على

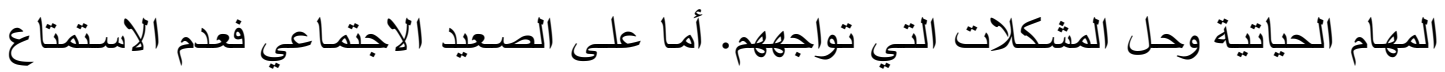

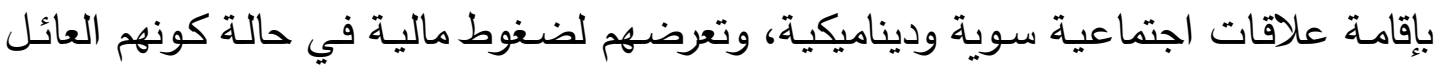
الوحيد لثقيقهم ذو اضطراب التوحد، مما يؤدي بهم إلى الابتعاد عن المجتهـ ونشـاطاته

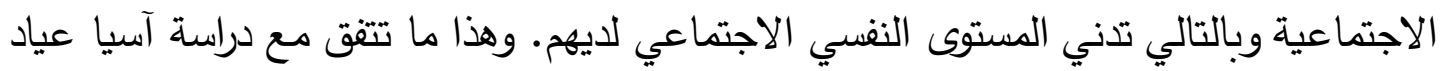

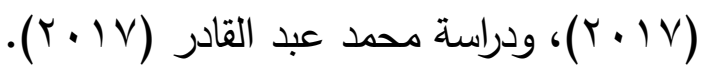

ويُعزي الباحث هذه النتيجة أيضًا إلى الخصائص النفسية الثخصية التي يتصف بها

أشقاء الأطفال التوحديين كضعف الثخصية والخوف من التفاعل الاجتماعي، وغياب نوعية

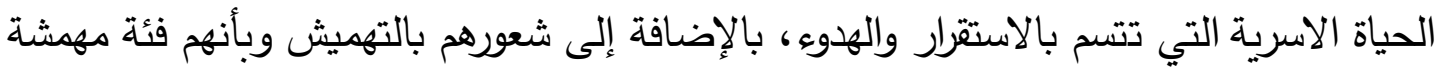

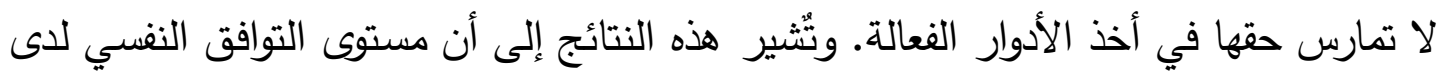


أشقاء الأطفال التوحديين كان أعلي من التوافق الاجتماعي، ويمكن إرجاع هذه النتيجة إلى انتثار

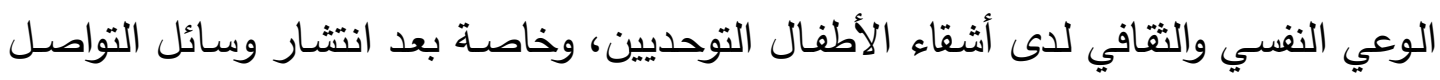

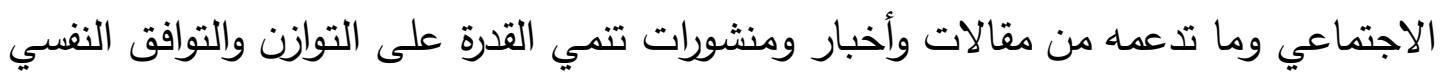
الفعال مع الإزمات، والقدرة على تحمل المسئولية ومواجهة المشكلات، كما يرجع سبب انخفاض مستوي التوافق الاجتماعي لدى أشقاء الأطفال التوحديين إلى وجود مشكلات اجتماعية لديهم مثل

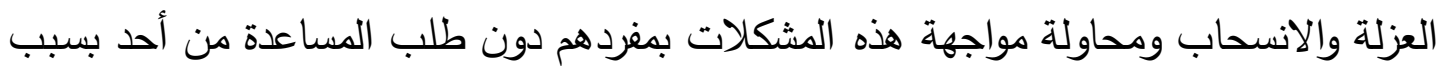
تدنٍ مستوى الذات لديهم، والخوف من الفشل، وصعوبة في القدرة على التوافق مع الأحداث والمواقف الجديدة. بالإضافة إلى عدم مقدرتهم على تحقيق التوازن بينهم وبين البيئة الاجتماعية

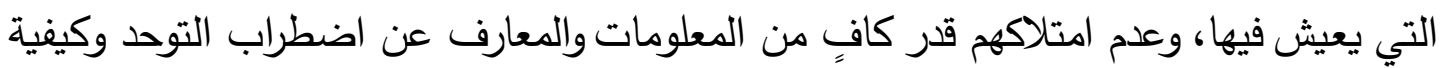

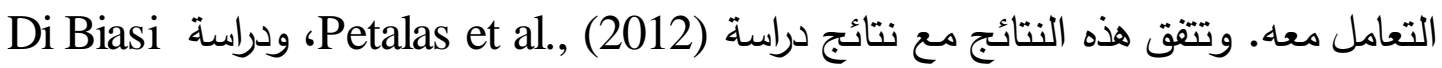
. Tsai, Cebula, \& Fletcher-Watson, (2016) ودراسة at al., (2015)

\section{نتيجـــة الفـــرض الثــانـــي ومنــاقشتهــا}

ينص الفرض الثاني على أنه: "توجد علاقة ارتباطيه دالة إحصائيا بين درجات عينة

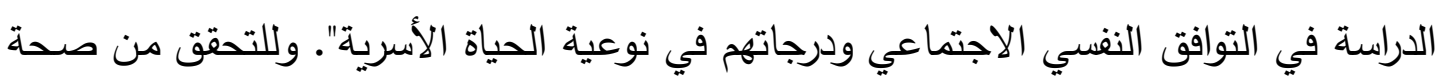

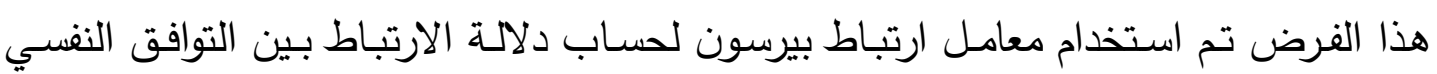
الاجتماعي ونوعية الحياة الأسرية لدى أثقاء الأطفال التوحديين، كما في جدول (V). جلدول (V) معاملات الارتباط بين درجات أفراد العينة في التوافق النفسي الاجتماعي ونوعية الحياةالأسرية

\begin{tabular}{|c|c|c|c|}
\hline (اللدرجة الكلية) & التواقق الاجتماعي & التواقق النفسي & التواقق النفسي الاجتماعي \\
\hline$* *,, q \leqslant \Psi$ & ***, ২৭६ & $* * *, 797$ & نوعية الحياة الأسرية \\
\hline
\end{tabular}

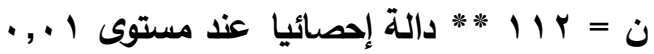

يتضح من الجدول (V) وجود علاقة ارتباط موجبة ذات دلالة إحصائية عند مستوى ال•, ·بين التوافق النفسي الاجتماعي وأبعاده (التوافق النفسي، التوافق الاجتماعي) ونوعية الحياة

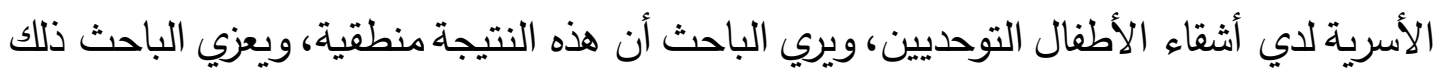

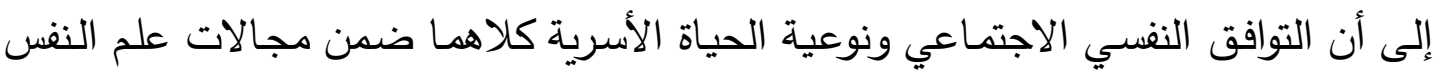


الإيجابي، الذي يهذف إلى أن يعيش الفرد حياة إيجابية تتسم بالجودة، وكذلك الاهتمام بالجانب

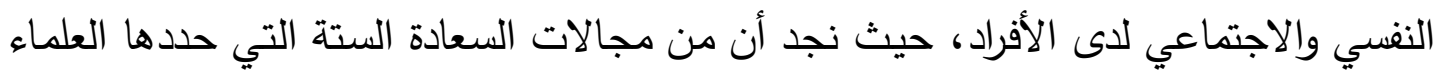
مجال العلاقات الإيجابية مع الآخرين متمثلًا في التوافق النفسي والاجتماعي. وهناك علاقـة حتميـة تفرضـها نوعيـة الحياة الأسرية خاصـة بالأسر التي يوجد بها أشخاص ذوي اضطراب التوحد، حيث كلما تقدمت مستوياتهم العمرية تزداد حاجتهم إلى الرعاية

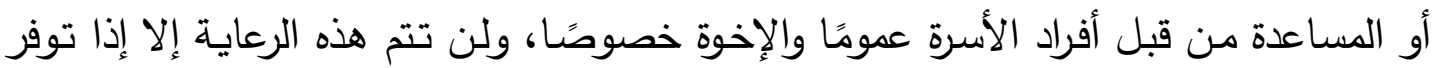
التوافق النفسي الاجتماعي لدى من يقدم إليهم هذه المسـاعدة، وهذه المساعدة تنعكس على نوعية الحياة الأسرية للأشقاء العاديين، فأشقاء الأطفال التوحديين في مرحلة الطفولة يواجهوا

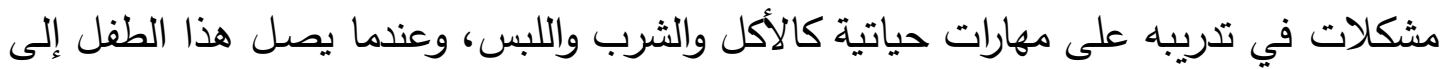

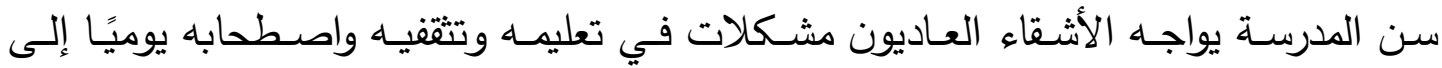
المدرسة، وحينما يصل إلى مرحلة المراهقة وما يصاحبها من تغيرات بيولوجية تتعلق بالرغبة في

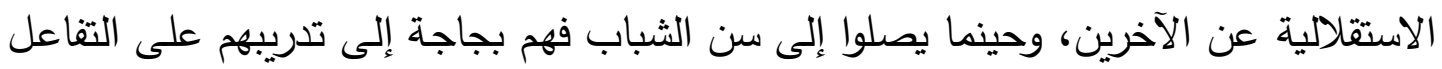

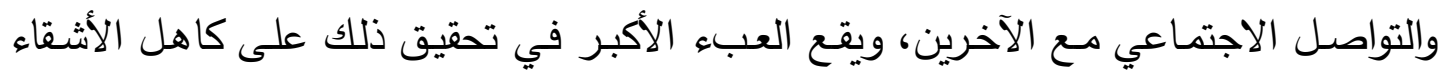

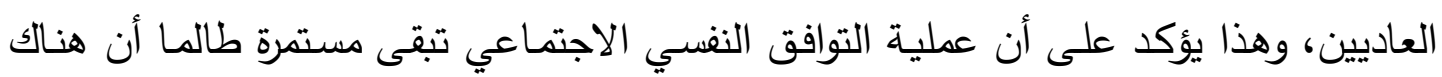
مطالب للطفل ذو اضطراب التوحد لا تنتهي مع كل مرحلة من مراحل النمو، بالتالي فنوعية

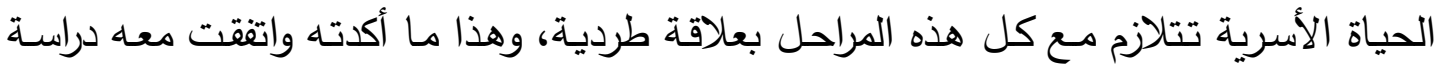

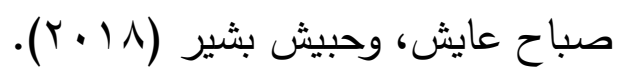

من هنا يتضح لنا العلاقة الإيجابية المتبادلة بين التوافق النفسي الاجتماعي ونوعية

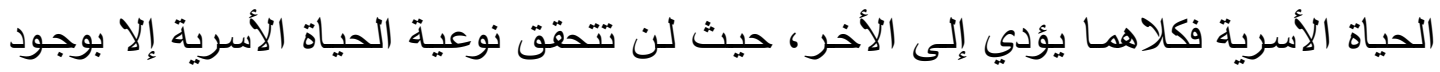

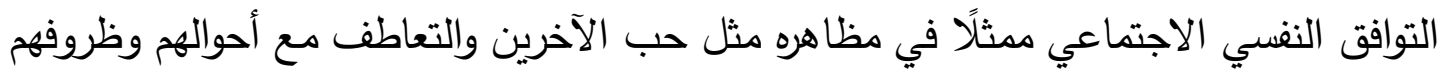

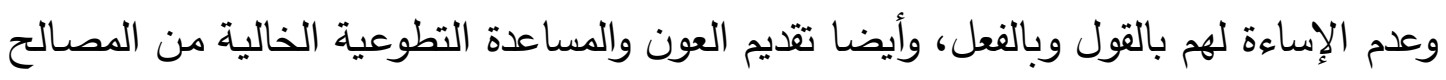

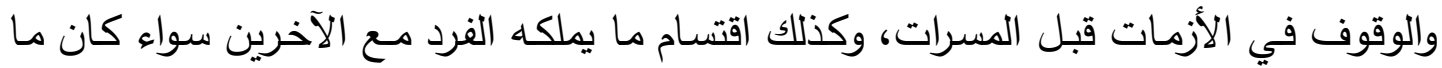

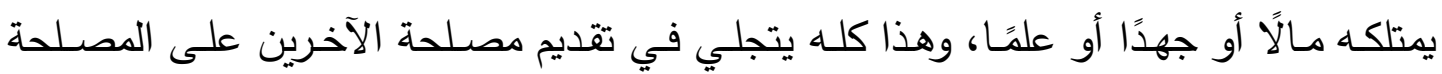
الثخصية للفرد. علاوة على أن التوافق يزيد من شعور الفرد بالكفاءة والقدرة التي تئودي بها إلي فئي

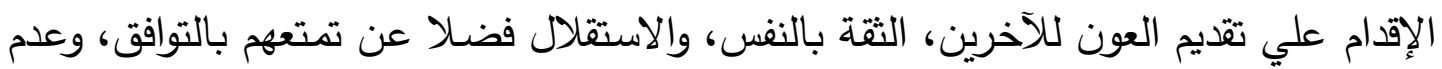


الاضطراب، والألفة والاجتماعية، الميل للتسامح، بالإضـافة إلى الإتزان الانفعالي، الإيجابية نحو الآخرين والاهتمـام بهم، الجاذبية والتقبل، الكرم والجود، ترسيخ النزعـة الجماعيـة دون الفردية، التوكيدية، المرونة، ارتفاع مستوي الطموح، التمتع بالذكاء والرضا وهذا يتفق مع دراسة

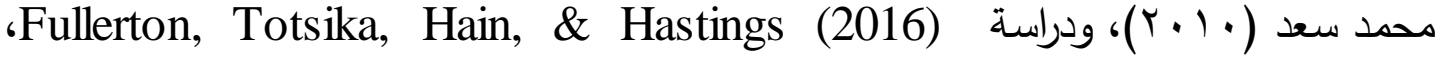
ودراسة (2017) (Eyuboglu, Baykara, \& Eyuboglu,

\section{نتيجـة الفــرض الثــالــث ومنــاقشتهــا}

ينص الفرض الثالث على أنه "توجد فروق دالة إحصائيا بين متوسطات درجات عينة

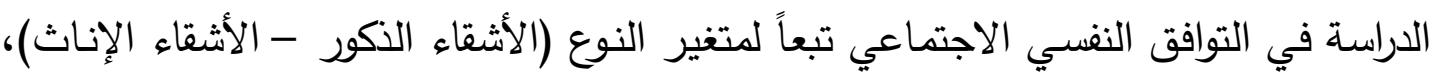
وتبعًا لمتغير العمر (الأشقاء الأكبر - الأشقاء الأصغر سنًا)". أ) الفـروق فـي التوافـق النفسي الاجتمـاعي تبعـاً للنـوع (الأشـقاء مسن الــذكور

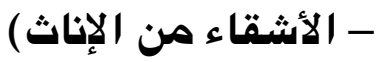

تم استخدام اختبار (ت) T-Test لحسـاب دلالــة الفروق بـين الأشقاء مـن الذكور

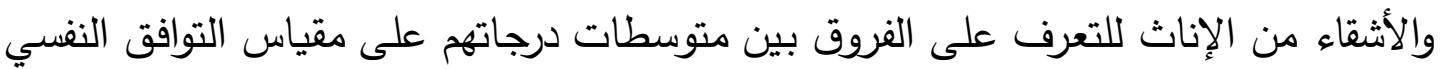
الاجتماعي بأبعاده والدرجة الكلية كما في جدول (^). جدول (A) دلالة الفروق في النوع (الأشقاء من الذكور -الأشقاء من الإناث) على مقيأس التوافق النفسي الاجتماعي الإني

\begin{tabular}{|c|c|c|c|c|c|c|}
\hline \multirow{2}{*}{ 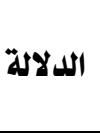 } & \multirow{2}{*}{ قيمة" ق" } & \multicolumn{2}{|c|}{ الأشقاء من الإناث(ن=|7l) } & \multicolumn{2}{|c|}{ الأشقاء من الذكود( ن= OI) } & \multirow{2}{*}{ التوافق النفسي الاجتماعي } \\
\hline & & الأنحراف(ع) & المتوسط & الأنحراف(ع) & المتوسط & \\
\hline$\cdot, \cdot 1$ & $* * 0, r \cdot r$ & $\{, \bullet \wedge$ & $\varepsilon 0, \vee v$ & 0,14 & $\xi 1, Y \xi$ & التواقق النفسي \\
\hline$\cdot, \cdot 1$ & $* * \Lambda, r \leq \varepsilon$ & $0,7 r$ & $\{7, \xi 1$ & $7,1 \cdot$ & rV, 17 & التواقق الاجتماعي \\
\hline$\cdot, \cdot 1$ & $* * 9,9 \leq Y$ & 9,70 & $9 Y, 11$ & $\Lambda, \cdot r$ & VA, rq & |للرجة الكلية \\
\hline
\end{tabular}

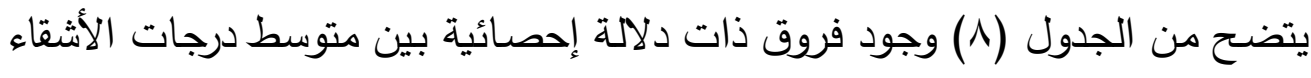

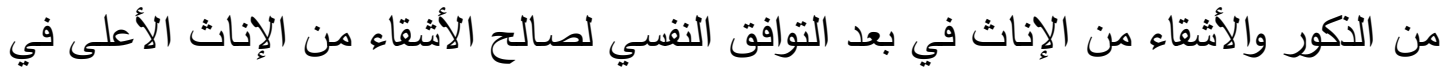

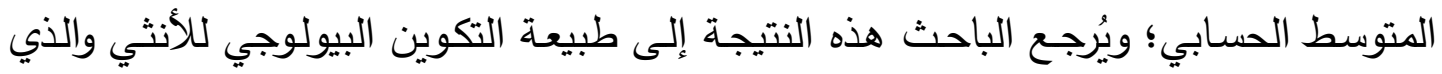


يتميز بتدفق المشاعر والعواطف وسرعة التأثر فالأنثي تميل للعاطفة أكثر من العقل، والثعور

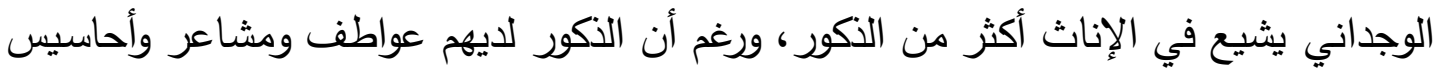

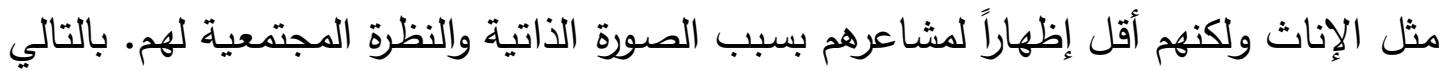

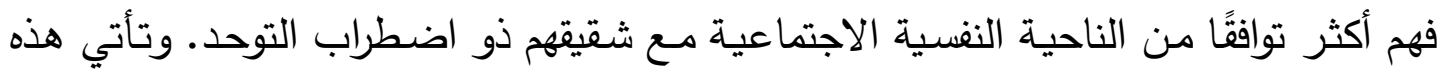

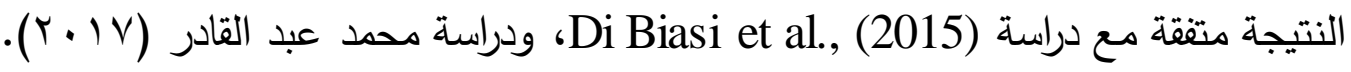

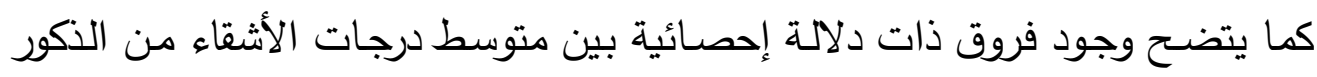

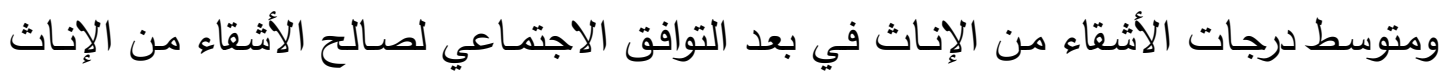

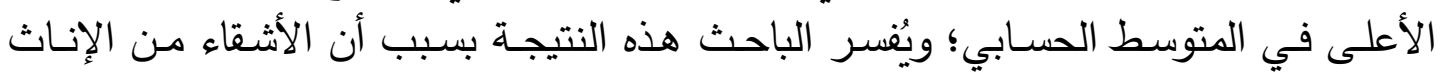

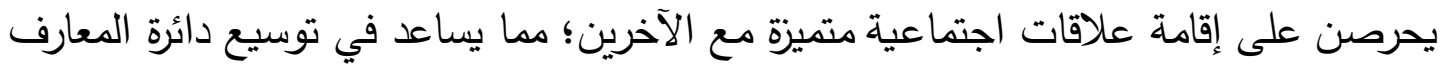

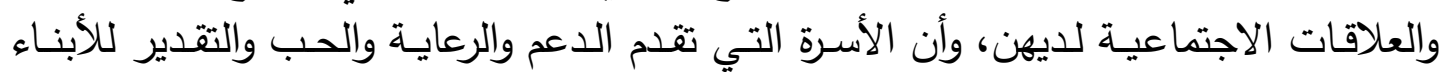

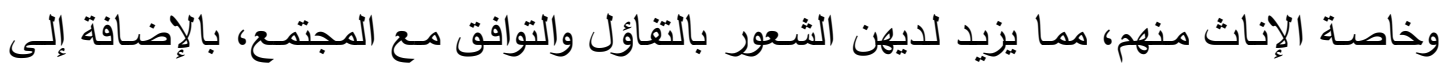

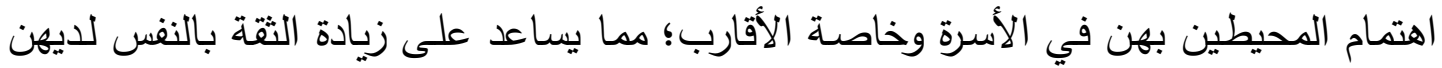

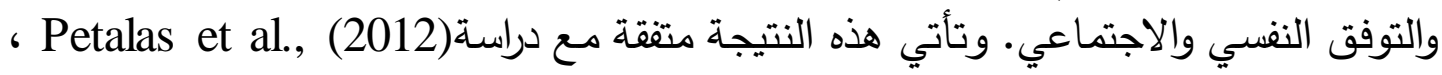

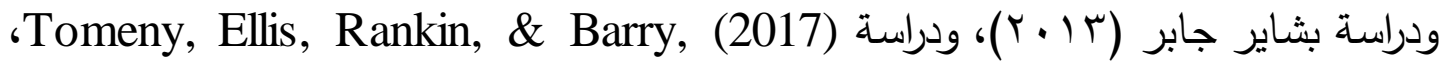

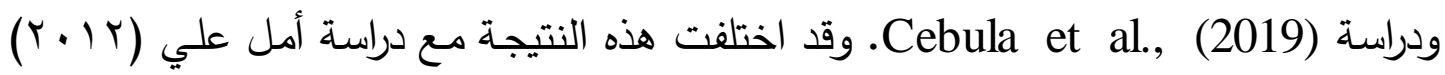
والتي توصلت لعدم وجود فروق بين جنس( الذكور والإناث) لأثثاء الأطفال التوحديين.

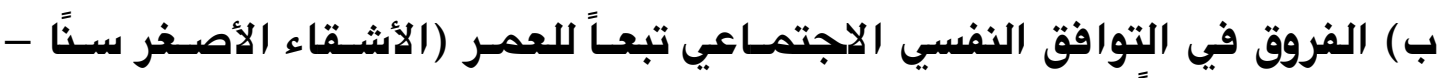

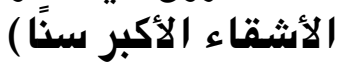

تم استخدام اختبار (ت) T-Test لحساب دلالة الفروق في العمر (الأشقاء الأصغر

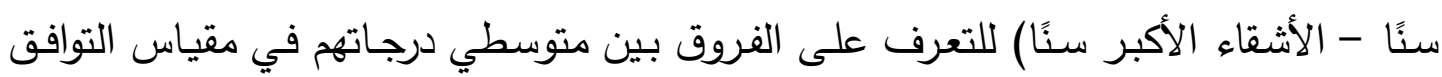

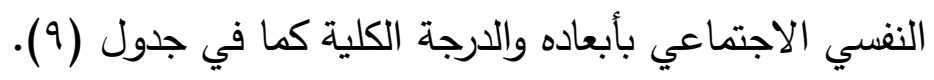

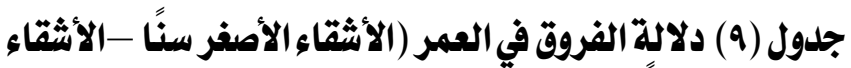

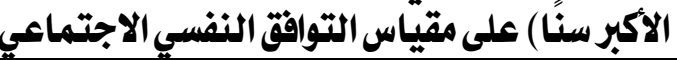

\begin{tabular}{|c|c|c|c|c|c|c|}
\hline \multirow{2}{*}{ 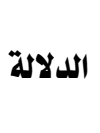 } & \multirow{2}{*}{ قيمة"ت" } & \multicolumn{2}{|c|}{ الأشقاء الاكبر سنًا (ن=00) } & \multicolumn{2}{|c|}{ الأشقاء الأصفر سنًا (ن=OV) } & \multirow{2}{*}{ مقياس التواقق النفسي الاجتماعي } \\
\hline & & الأنحراف(ع) & المتوسط & الأنحراف(ع) & المتوسط & \\
\hline$\cdot, \cdot 1$ & $* * \xi$, ov. & $\xi, 14$ & $\$ 0, \mathrm{V \uparrow}$ & 0,19 & $\$ 1, V Y$ & التوافق النفسي \\
\hline$\cdot,+1$ & $* * ฯ, \wedge 90$ & $0, \gamma$. & $\leqslant 4, r T$ & $9, V r$ & $r \Lambda, r l$ & التوافق الاجتماعي \\
\hline$\cdot, \cdot 1$ & $* * \wedge, \bullet \Delta 0$ & $\Upsilon, \Lambda T$ & $94, \bullet 9$ & 1,97 & vq,qr & اللرجة الكلية \\
\hline
\end{tabular}

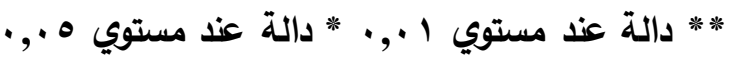


يتضـح من الجدول (9) وجود فروق ذات دلالة إحصائية بين متوسط درجات الأشقاء

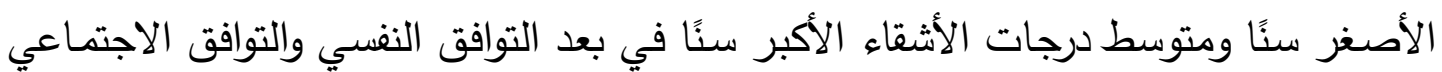
لصالح الأشقاء الأكبر سنًا في المتوسط الحسابي؛ ويُرجع الباحث هذه النتيجة النئة إلى أن الأشقاء

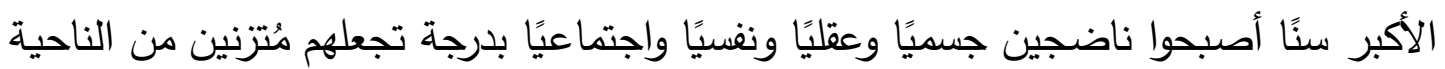

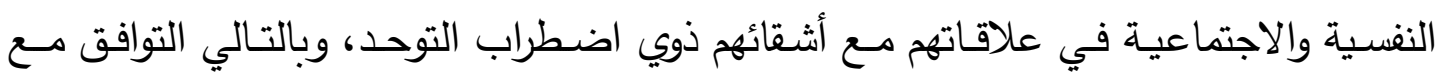

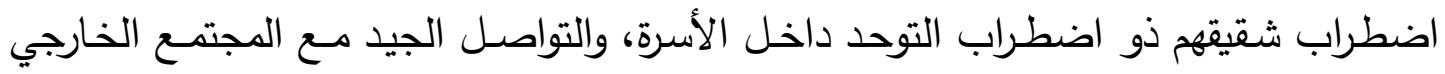

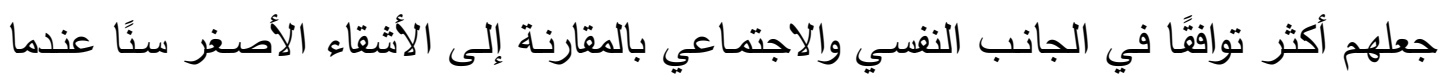

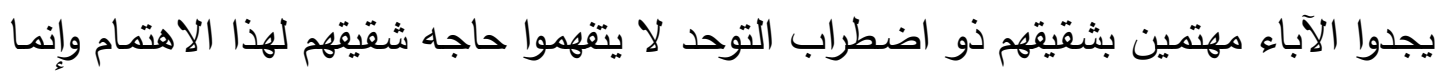

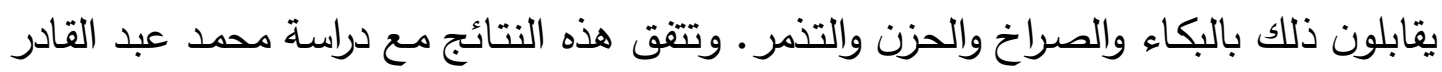

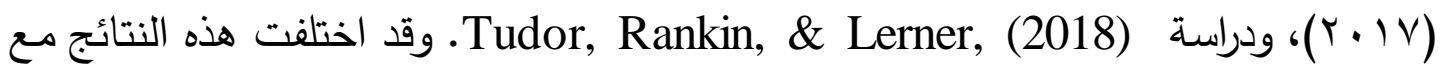

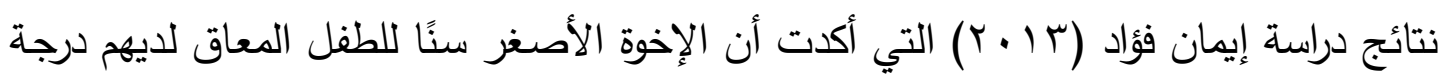

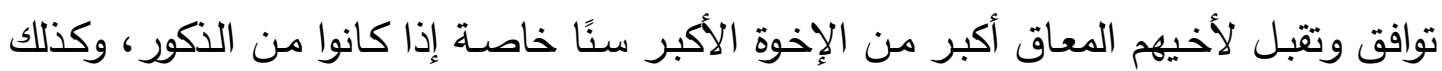

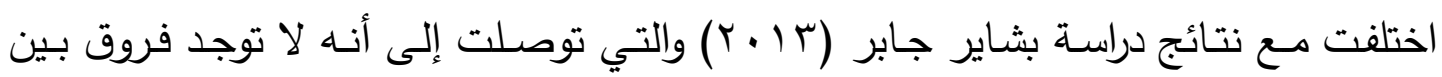

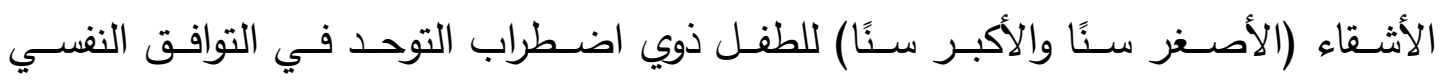
الاجتماعي، ويرجع الباحث هذا الاختلاف إلى اختلاف عينة الدراسة من حيث العدد العدة والعمر والطبيعة المكانية والتتشئة الاجتماعية.

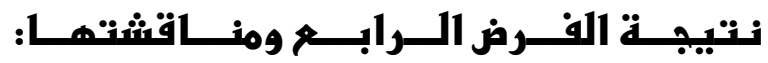

ينص الفرض الرابع على أنه "توجد فروق دالة إحصائيا بين متوسطات درجات عينة

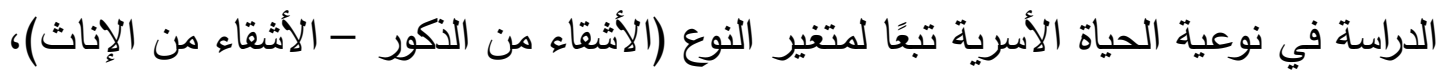

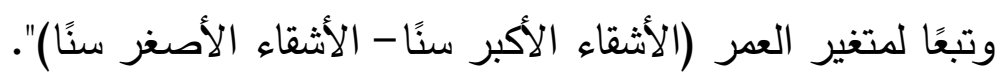

أ ) الفروق في نوعيتة الحياة الأسريتة تبعاً للنوع ( الأشقاء من الذكور - الأشقاء من الإناث) تم استخدام اختبار (ت) T-Test لحسـاب دلالــة الفروق بين الأشقاء مـن الذكور والأثقاء من الإناث للتعرف على الفروق بين متوسطي درجاتهم في مقياس نوعية الحياة الأسرية كما في جدول (·) (1). 
جدول (• (1) دلالة الفروق في النوع (الأشقاء من الذكور - الأشقاء من الإناث) على مقياس نوعية الحياة الأسرية

\begin{tabular}{|c|c|c|c|c|c|c|}
\hline \multirow{2}{*}{ الدلالة الد } & \multirow{2}{*}{ قيمة"ت״” } & \multicolumn{2}{|c|}{ الأشقاء من الإناث(ن=|7) } & \multicolumn{2}{|c|}{ الأشثقاء من الدكور(ذ=10I) } & \multirow{2}{*}{ نوعية الحياة الأسرية } \\
\hline & & الأنحراف(ع) & المتوسط & الأنحراف(ع) & المتوسط & \\
\hline$\cdot, \cdot 1$ & $* * \wedge, \wedge$. & $7,7 \mathrm{~V}$ & $9 r, 11$ & $\vee, \wedge Y$ & $\Lambda \cdot,+\wedge$ & اللرجة الكلية \\
\hline
\end{tabular}

*** دالة عند مستوي I +,.

يتضح من الجدول ( • () وجود فروق ذات دلالة إحصائية بين متوسط درجات الأشقاء

من الاككور ومتوسط درجات الأشقاء من الإناث في نوعية الحياة الأسرية لصالح الأشقاء من الإناث الأعلى في المتوسط الحسابي؛ ويُفسر الباحث هذه النتيجة بأن النوع يلعب دور كبير في

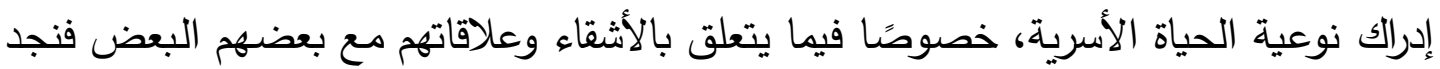

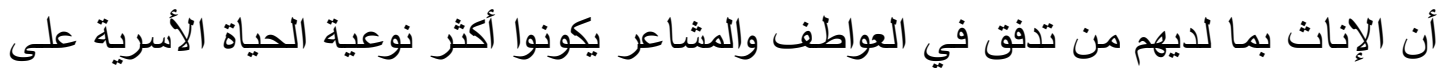
عكس الذكور الذين يميلون للشجار مع أشقائهم، وخاصـة ذوي اضطراب التوحد، والأنثي تكون أكثر ارتباطًا بالمنزل وأكثر توجدًا فيه بالتالي تكون أكثر قدرة على مواجهة الضغوط الحياتية ويجعل لديها الرغبة في تحقيق النجاح الأسري، بالتالي فنوعية الحياة الأسرية لديهن أمر أساسي تسعي إليه كل أنثي، وذلك على عكس الذكور يكونوا أكثر تهميشًا في الأمور الأسرية فتقل لديهم نوعية الحياة الأسرية. وبشكل عام تعتبر الإناث أكثر مسايرة للمناخ الأسري وأكثر ارتباطا

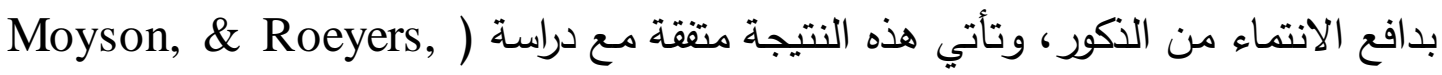

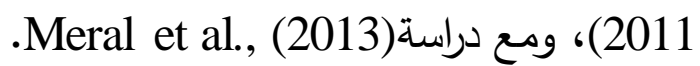

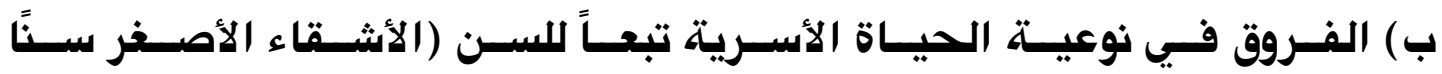
- الأشقاء الأكبر سنًا )

تم استخدام اختبار (ت) T-Test لحساب دلالـة الفروق بين الأشقاء الأصسغر سـًا والأشقاء الأكبر سنًا، وللتعرف على الفروق بين متوسطي درجاتهم في مقياس نوعية الحياة الأسرية كما في جدول (1).

جدول (11) دلالةًإلفروق في العمر (الأشقاء الأصفر سينًا

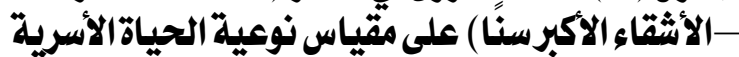

\begin{tabular}{|c|c|c|c|c|c|c|}
\hline \multirow{2}{*}{ الدلالة الد } & \multirow{2}{*}{ قيمة"״” } & \multicolumn{2}{|c|}{ الأشقاء الأكبر سنًا (ن=00) } & \multicolumn{2}{|c|}{ الأشقاء الأصفر سنًا (ن= OV) } & \multirow{2}{*}{ نوعية الحياة الأسرية } \\
\hline & & الأنحراف(ع) & المتوسط & الأنحراف(ع) & المتوسط & \\
\hline$\cdot, \cdot 1$ & $* * Y$, YOI & $7, \wedge \mathrm{r}$ & $9 r, \cdot 9$ & $\wedge, 0 \wedge$ & $\wedge 1,\{\xi$ & الدرجة الكلية \\
\hline
\end{tabular}


يتضح من الجدول (11) وجود فروق ذات دلالة إحصائية بين متوسط درجات الأشقاء

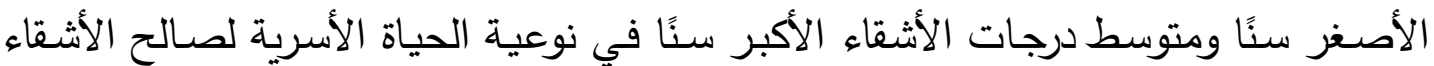
الأكبر سنًا الأعلى في المتوسط الحسابي؛ وُيفسر الباحث هذه النتيجة أن الأثقاء الأكبر سنًا

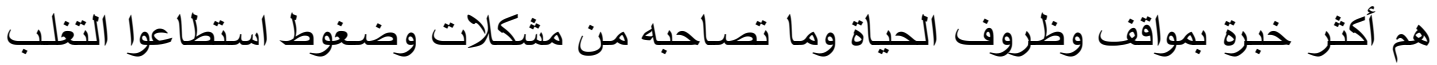
عليها وأصبح لديهم مرونة نفسية واستمتاع بهذه الحياة، وكذلك وصلوهم لدرجة كبيرة من النضج ونس العقلي والجسمي والنفسي الذي يتمتعون بـه مـع مرور الزمن؛ مما يجعلهم أكثر تعاونًا وتكيفًا

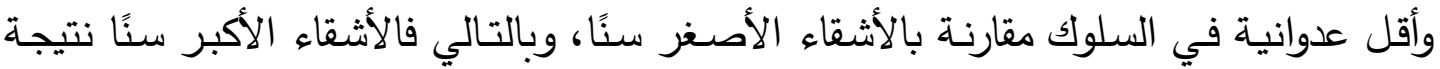

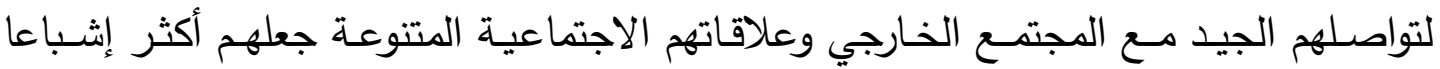

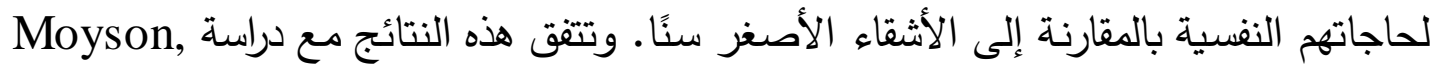
. Tomeny, Ellis, Rankin, \& Barry, (2017) \& Roeyers, (2011)

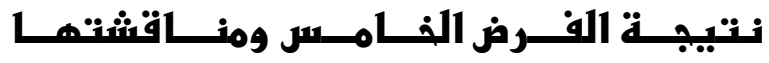

ينص الفرض الخامس على أنـه "يُسهم التوافق النفسي الاجتماعي في التنبؤ بنوعية الحياة الأسرية لاى أشقاء الأطفال التوحديين". وللتحقق من صحة هذا الفرض، لتوض وقام الباحث

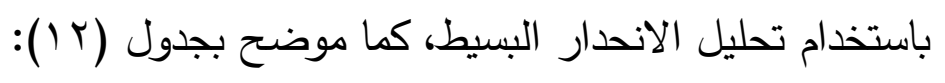

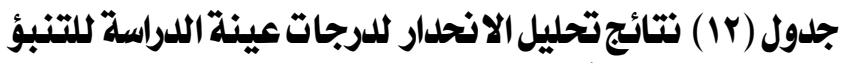

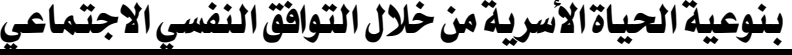

\begin{tabular}{|c|c|c|c|c|c|c|c|c|}
\hline 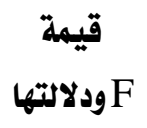 & قيمة (T) & قيمة بيتا & المعياري & قيمة B & 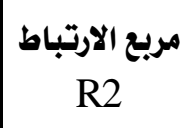 & $\begin{array}{l}\text { الارتباط المتدد } \\
\text { المتباد }\end{array}$ & المتنفيرات المستقلة & المتفير التابع \\
\hline \multirow[b]{2}{*}{$* * \Lambda \wedge \mathcal{E}, \mathbf{Y}$} & $* * \xi, 1 \xi$ & & r,or & $1 ., 77$ & \multirow[b]{2}{*}{,$\wedge \wedge 9$} & \multirow[b]{2}{*}{ "थ } & الثابت & اللرجة الكلية \\
\hline & $* * \uparrow q, \gamma$ & ז & 落, & , ^^० & & & النفسي الاجتماعي اللكقية للتقافق & لنوعية الحياة \\
\hline
\end{tabular}

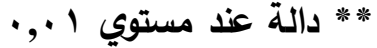

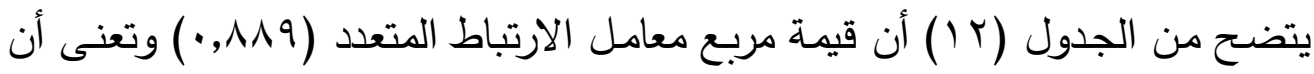

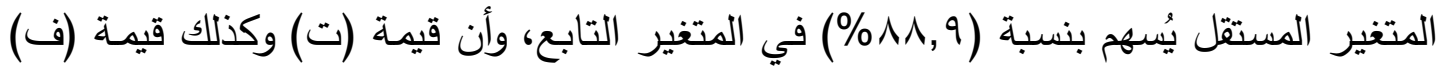
دالة إحصائيا عند مستوى (1 (, ·) مما يؤكد تأثير المتغير المستقل على المتغير التابع. 


\section{ويمكن صياغة معادلة الانحدار وهي:}

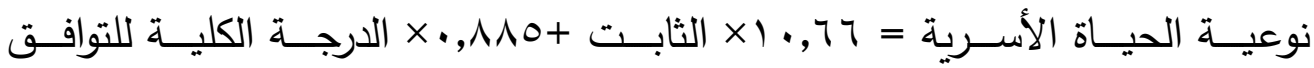

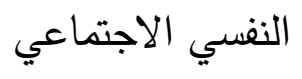

من نتائج الفرض الخامس يتضح أن الدرجة الكلية للتوافق النفسي الاجتماعي ساهدت في التنبؤ بنوعية الحياة الأسرية لاى أثقاء الأطفال ذوي اضطراب التوحد، ويمكن تفسير ذلك إلى العلاقة الارتباطية القوية بين التوافق النفسي الأسري ونوعية الحياة الأسرية حيث يعتبر التوافق النفسي الأسري من ضمن مجالات نوعية الحياة بصفة عامة وأحد فروعها، وهو يعكس شعور الفرد بمدي تماسك الأسرة وما تقدمه لهولاء الأثقاء من استقرار وشعور بالراحة النفسية، حيث أن قدرة الأشقاء على التوافق النفسي الاجتماعي مع متغيرات وظروف إعاقة أشقائهم ذوي اضطراب التوحد يعتبر من مقومات وأساسيات نوعية الحياة الأسرية الجيدة. وما يؤكد هذا التنبؤ

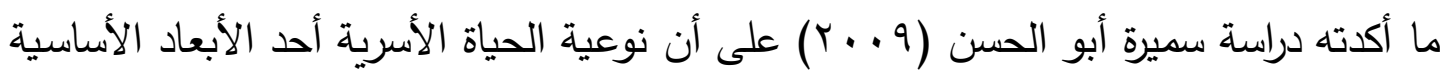
التي تثكل نوعية الحياة للي الفرد، وتثير إلى إدرالك الفرد والإحساس الذي يشعر به تجاه نوعية حياته الأسرية والمعيشية ومدي جودتها أو سوئها، وما يترتب على ذلك من إحساس بالتوافق والقبول أو الاستياء والرفض لهذه الحياة، ومدي إحساسه بالسعادة أو الثقاء فيها.

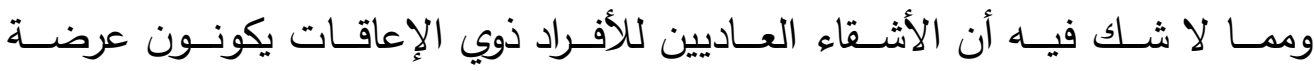
أكثر مـن غيـرهم للمشـكلات، وأن مـــى هـــه المشـكلات أو خطورتهــا يتوقـف بالدرجــة الأولى على توافق الآخرين في الأسـرة خاصـة الوالدان فـإذا كانـت هنـاك مهارات مواجهـة مناسبة، ونمط تواصل وبيئة تتسم بالدعم المتبادل فينتج عن ذلك التأثير الإيجابي نحو الأخوة؛ بالتـالي تتحقق نوعيـة الحيـاة بمفهومـا الإيجابي، وتـأتي هذه النتائج منسجمة مـع نتائج دراسة (Abrams، ودراسة (2009) (2015) (Markowitz et al., 
في ضوء أدبيات الدراسة ونتائجها تم وضع مجموعة من التوصيات التي قد تساعد في تعزيز التوافق النفسي الاجتماعي ونوعية الحياة الأسرية لدى أثقاء الأطفال ذوي اضطراب التوحد: 1-ضـرورة إعداد برامج تأهيليـة لأشقاء الأطفال ذوي اضطراب التوحد تستهدف تنميـة التوافق النفسي الاجتماعي؛ لفاعليتها في نوعية الحياة الأسرية. ץ-ضـرورة اهتمـام الآبـاء بتنميـة السلوكيات الإيجابيـة لدى أبنائهم مثل التوافق النفسي الاجتماعي وتحمل المسئولية والتعاون والتسامح والتعاطف. r-توعية أفراد الأسرة وخاصـة الآباء بضرورة الاهتمام بالجوانب الخاصـة بنوعية الحياة الاسرية لأبنائهم. ع - تحسين الظروف الأسرية لتأثيرها على نوعية الحياة لدى أفراد الأسرة. ه-ضـرورة الاهتمـام بتقديم الإرشـاد النفسي والاجتمـاعي مـن خـلال أخصـائيين مُدربين ومتخصصين لمسـاعدة أشقاء الأطفال ذوي اضطراب التوحد على حل مشكلاتهم، والقيام بأدوارهم الأسرية بصورة تتسم بالجودة والتميز. צ-ضرورة تفعيل برامج التدخل المبكر لرفع الأداء الوظيفي الأسري لأشقاء الأطفال ذوي

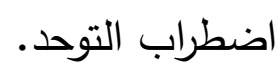




\section{المـــراجـ}

\section{أولاً: المــراجـــع العــربيــة :}

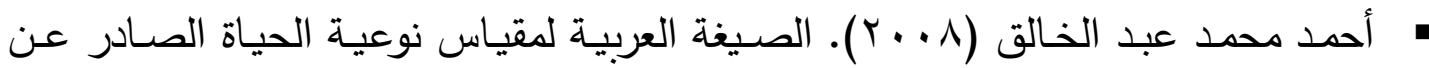

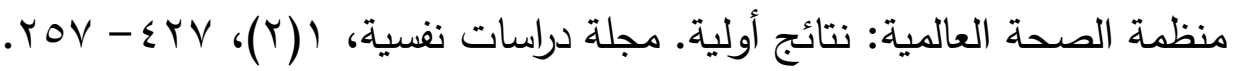

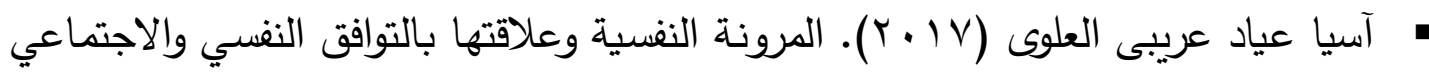
لاى الطلبة في الأردن، رسالة ماجستير غير منشورة، كلية العلوم التربوية والنفسية، جامعة

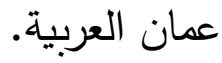

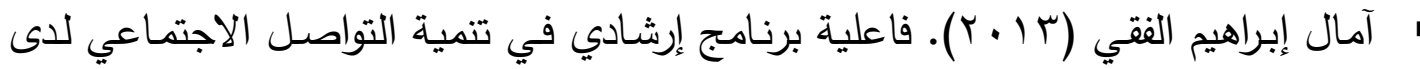
مريضات السرطان وأثره على جودة الحياة الأسرية. مجلة كلية التربية جامعة بنها - كلية

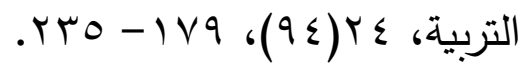
أماني عبد المقصود، وإسراء عبد المقصود (r • ب). مقياس التوافق النفسي للأطفال. القاهز: مكتبة الأنجلو المصرية. أماني عبدالمقصود عبدالوهاب، وسميرة محمد إبراهيم شند (· ( †). جودة الحياة الأسرية وعلاقتها بفاعلية الذات لدى عينة من الأبناء المراهقين، المؤتمر السنوي الخامس عشر -

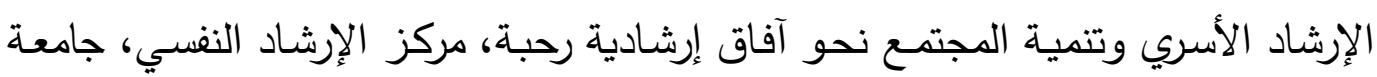
عين شمس، المجد الثاني.

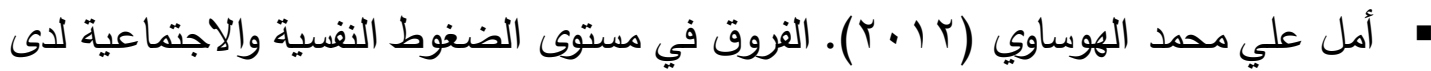
أخوة وأخـوات الأطفال التوحديين وفقاً لمستوى التعليم ومستوى دخل الأسرة في مدينـة الرياض، رسالة ماجستير، كلية الدراسات العليا، جامعة الخليج العربي بالبحرين. إيمان فؤاد كاشف (ع ( ب). التشخيص الفارق لذوى الإعاقة العقلية واضطراب التوحد. مجلة علمية دورية محكمة يصدرها مركز المعلومات التربوية والنفسية والبيئية بكلية التربية

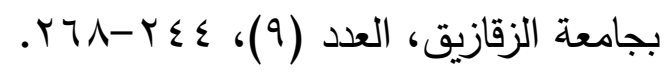


إيمـان فؤاد محمد كاشـف(ب ا • Y). اتجاهـات أخـوه الطفل المعـاق كقوة داعمـة للمســاندة والتمكين المجتمي مجلة التربية الخاصة جامعة الزقازيق - كلية علوم الإعاقة والتأهيل،

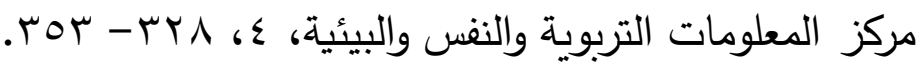

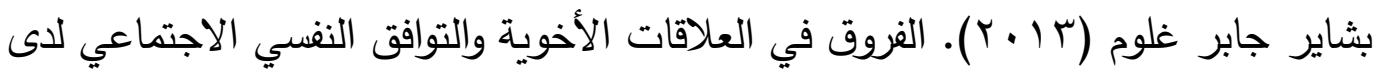

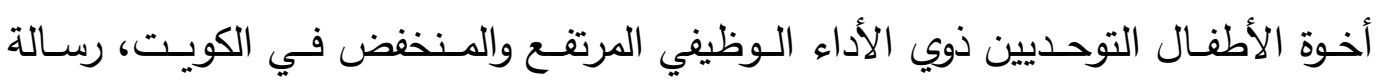
ماجستير، كلية الدراسات العليا، جامعة الخليج العربي بالبحرين. بيان يحيى الحديد (Y V ا Y). المشكلات الاجتماعية والانفعالية وعلاقتها بالتكيف النفسي لدى إخوة ذوي اضطراب التوحد، رسالة ماجستير، كلية العلوم التزبوية والنفسية، جامعة عمان العربية. جبر محمد جبر (T/ + r). علم النفس الإيجابي. القاهرة: الحنفي للطباعة الحديثة. حامد عبد السلام زهران (ך r). الصحة النفسية والعلاج النفسي. (ط ؟). القاهرة: عالم الكتب.

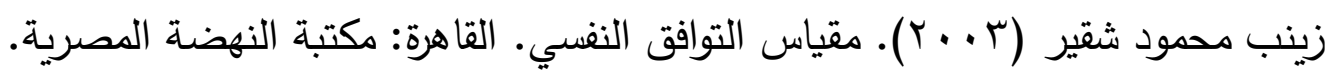

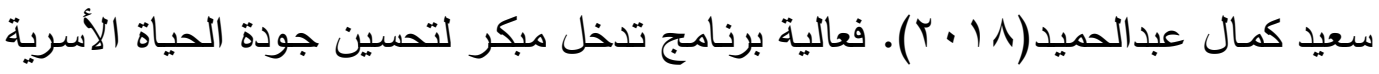
الأطفال التوحديين وأثره على الوعي الذاتي لأطفالهم في سن ما قبل المدرسة. مجلة بلته كلية

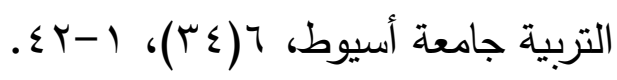

سميرة أبو الحسن عبدالسلام النجار (9 ـ . ؟). فاعلية برنامج إرشادي لتحسين نوعية الحياة الأسرية في خفض حدة الانفعالات السلبية لدى إخوة المعاقين عقليا، المؤتمر الإقليمي الأول:

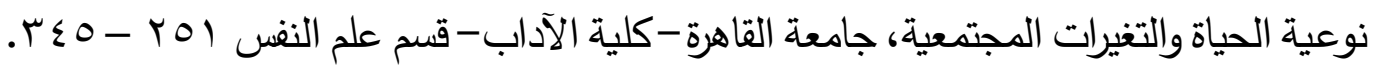
سهير إبراهيم محمد ( ع . . r). المخاوف وعلاقتها بالتوافق النفسي والاجتماعي لدى أطفال

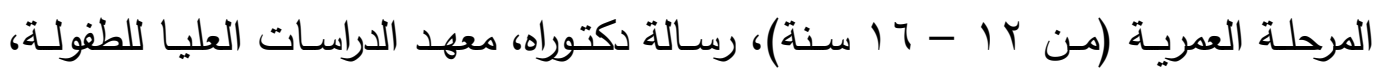
جامعة عين شمس.

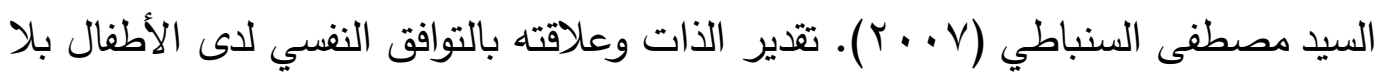

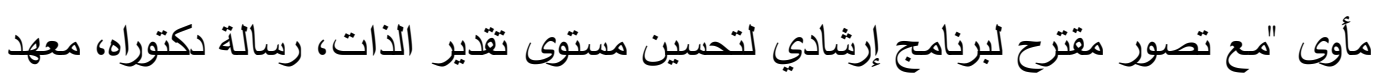
الدراسات العليا للطفولة، جامعة عين شمس. 
• صباح عايش، وحبيش بشير (1) • (Y). الكفاءة الذاتية للى إخوة المعاقين عقليا وعلاقتها

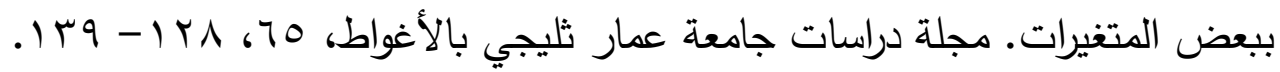
" صفاء عبدالزهرة حميد (9 ( ب). التكيف النفسي والاجتماعي وعلاقته بالاتجاه نحو الهجرة

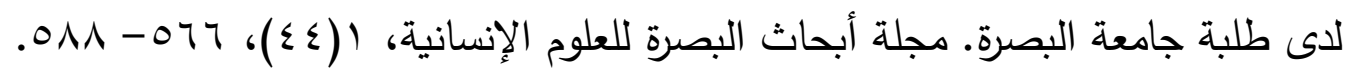
صلاح الدين محمد توفيق( • ( ب). فلسفة جودة الحياة للطفولة العربية المعاقة، المؤتمر

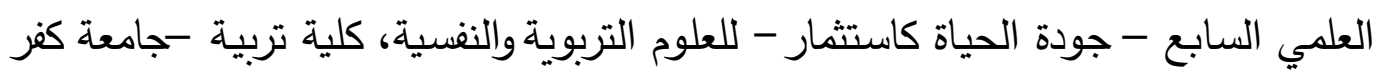

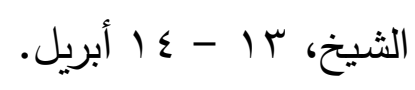
عادل عبداللهمحد (0 ( ب ). أساليب تثخيص وتقييم اضطراب التوحد. الرياض: دار الزهراء.

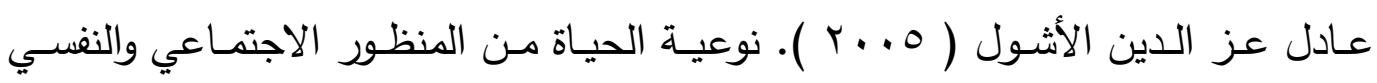

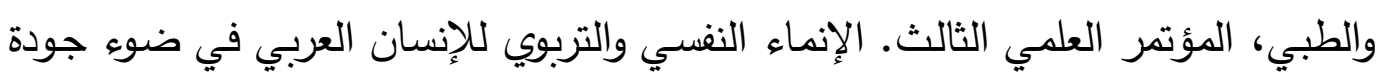

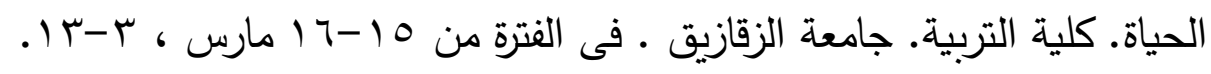

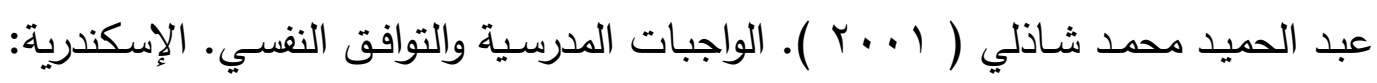
المكتبة الجامعية.

علا محمد الطبياني، وإبراهيم زكي الصاوي (10 • †). استخدام برنامج قائم على الألعاب

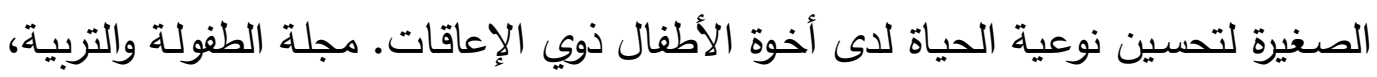

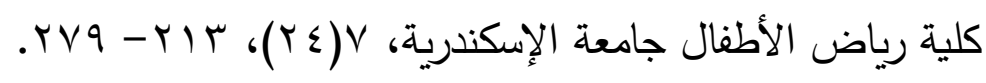
علاء الدين كفافي، وسهير محمد سالم، وعفاف عبد المحسن الكومي (9 . . ب). في تربية المعوقين. القاهرة: دار الفكر العربي. عيد جلال أبو حمزة، وسجي عبدالله يونس (9 ( • ب). فاعلية برنامج إرشادي لتحسين جودة

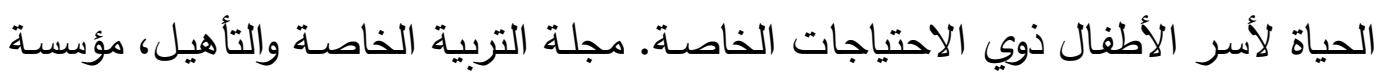

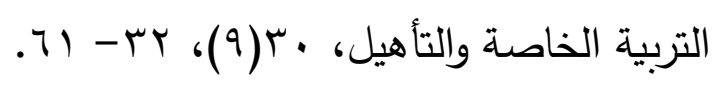

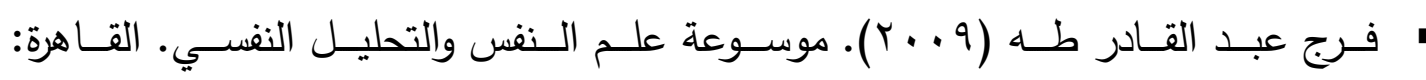
مكتبة الأنجلو المصرية. 
فيوليت فؤاد إبراهيم، وحافظ نبيل عبد الفتاح، ومياة أحمد مختار (7 ( ب). الخصـائص

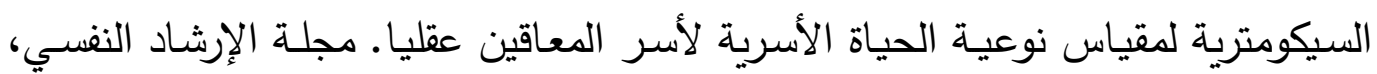

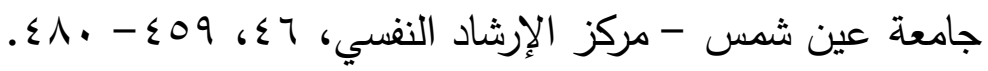

محمد سعد حامد (• ( • ). فاعلية برنامج إرشادي لتتمية التوافق النفسي في مواجهة أحداث

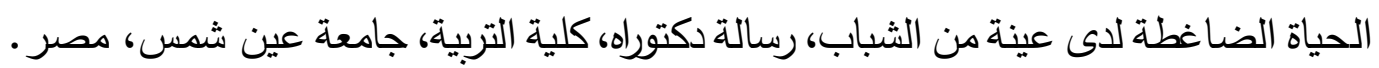

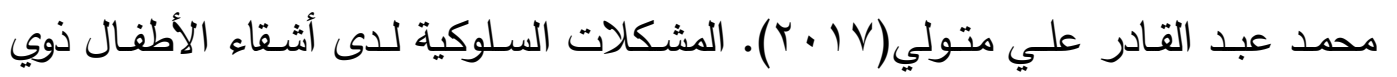
اضطراب طيف التوحد كمـا تدركها الأمهات وعلاقتها بحاجـاتهم النفسي. مجلة التربيـة الخاصة والتأهيل - مركز المعلومات التربوية والنفسية والبيئية بكلية التربية جامعة الزقازيق

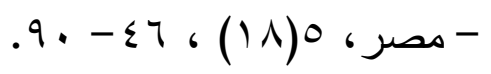

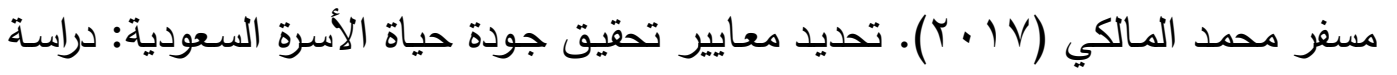

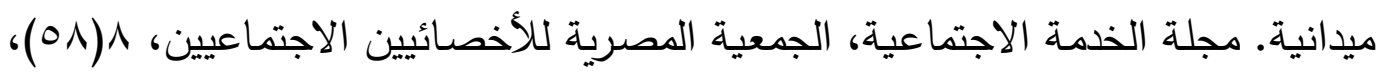
$. r \cdot T-$ YNT

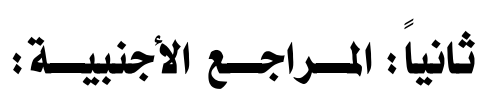

- Abrams, M. S. (2009). The Well Sibling: Challenges and Possibilities. American Journal of Psychotherapy, 63(4), 305-317. doi:10.1176/appi.psychotherapy.2009.63.4.305

- Alanani, H. (2000). Psychological Health. Amman: Dar Al-Fikr.

- American Psychiatric Association(ABA) (2013). Diagnostic and Statistical Manual of Mental Disorders (5th ed.). Washington, DC: Author.

- Bitsika, V., Sharpley, C. F., \& Mailli, R. (2014). The Influence of Gender, Age, psychological Resilience and Family Interaction Factors Upon Anxiety and Depression in Non-Autism Spectrum Disorder Siblings of Children with an Autism Spectrum Disorder. British Journal of Guidance \& Counselling, 43(2), 216-228. doi:10.1080/03069885.2014.950944 
- Bitsika, V., Sharpley, C. F., \& Mailli, R. (2014). The Influence of Gender, Age, Psychological Resilience and Family Interaction Factors Upon Anxiety and Depression in Non-Autism Spectrum Disorder Siblings of Children with an Autism Spectrum Disorder. British Journal of Guidance \& Counselling, 43(2), 216-228. doi:10.1080/03069885.2014.950944

- Cebula, K., Gillooly, A., Coulthard, L. K., Riby, D. M., \& Hastings, R. P. (2019). Siblings of Children with Williams Syndrome: Correlates of Psychosocial Adjustment and Sibling Relationship Quality. Research in Developmental Disabilities, 94, 103496. doi:10.1016/j.ridd.2019.103496

- Cholewicki, M. (2015). Services : Received and Parental Perception of Quality of Life for Children with Autism Spectrum Disorder. University of South Carolina, ProQuest Dissertations Publishing.

- Di Biasi, S., Trimarco, B., D’Ardia, C., Melogno, S., Meledandri, G., \& Levi, G. (2015). Psychological Adjustment, Social Responsiveness and Parental Distress in an Italian Sample of Siblings of Children with High-Functioning Autism Spectrum Disorder. Journal of Child and Family Studies, 25(3), 883-890. doi:10.1007/s 10826-015-0256-X

- Eyuboglu, M., Baykara, B., \& Eyuboglu, D. (2017). Assessment of Psychosocial Features and Quality of Life of Typically Developing Siblings of Children who Diagnosed with Autism Spectrum Disorder. Anadolu Psikiyatri Dergisi,18(3):265-272, doi:10.5455/apd.232717

- Fullerton, J. M., Totsika, V., Hain, R., \& Hastings, R. P. (2016). Siblings of Children with Life-Limiting Conditions: Psychological Adjustment and Sibling Relationships. Child: Care, Health and Development, 43(3), 393-400. doi:10.1111/cch.12421 
- Joseph Y. C.,\& Kelly Y. C.(2016). Psychological Adjustment of Siblings of Children with Autism Spectrum Disorder in Hong Kong. East Asian Arch Psychiatry,26(4),141-7

- Leadbitter, K., Aldred, C., Mc Conachie,H., Le Couteur, A., Kapadia,D. Charman , T.\& Macdonald ,W., et al.(2018).The Autism Family Experience Questionnaire (AFEQ): An Ecologically-Valid, Parent-Nominated Measure of Family Experience, Quality of Life and Prioritised Outcomes for Early Intervention, "Jounal of Autism and Develomental Disorders, 48(4),1052-1062.

- Lee, C. eun, Burke, M. M., Arnold, C. K., \& Owen, A. (2018). Comparing Differences in Support needs as Perceived by Parents of Adult Offspring with Down Syndrome, Autism Spectrum Disorder and Cerebral Palsy. Journal of Applied Research in Intellectual Disabilities. doi:10.1111/jar.12521

- lerardo, M. (2017). Effect of Psychoeducation on Disorder Knowledge, Self-Awareness, Self-Esteem, and Social Communication Behaviors in Adolescents with High Functioning Autism. Hofstra University, ProQuest Dissertations Publishing.

- Lovell, B., \& Wetherell, M. A. (2016). The Psychophysiological Impact of Childhood Autism Spectrum Disorder on Siblings. Research in Developmental Disabilities, 49, 226-234. https://doi. org/10.1016/j.rldd.2015.11.023.

- Markowitz, L. A., Reyes, C., Embacher, R. A., Speer, L. L., Roizen, N., \& Frazier, T. W. (2016). Development and Psychometric Evaluation of a Psychosocial Quality-of-Life Questionnaire for Individuals with Autism and Related Developmental Disorders. Autism, 20(7), 832-844. doi:10.1177/1362361315611382 
- McHale, S. M., Updegraff, K. A., \& Feinberg, M. E. (2015). Siblings of Youth with Autism Spectrum Disorders: Theoretical Perspectives on Sibling Relationships and Individual Adjustment. Journal of Autism and Developmental Disorders, 46(2), 589-602. doi:10.1007/s 10803-015-2611-6

- Meral, B. ; Cavkaytar, A. ; Turnbull, A. \& Wang, M. (2013). Family Quality of Life of Turkish Families who have Children with Intellectual Disabilities and Autism. Research and Practice for Persons with Severe Disabilities, 38 (4), 233 - 246.

- Moyson, T., \& Roeyers, H. (2011). The Quality of Life of Siblings of Children with Autism Spectrum Disorder. Exceptional Children, 78(1), 41-55. doi:10.1177/001440291107800103

- O’Neill, L. P., \& Murray, L. E. (2016). Anxiety and Depression Symptomatology in Adult Siblings of Individuals with Different Developmental Disability Diagnoses. Research in Developmental Disabilities, 51-52, 116-125. doi:10.1016/j.ridd.2015.12.017

- Olson, D. (2011). FACES IV and the Circumplex Model: Validation Study. Journal of Marital \& Family Therapy, 37(1), 64-80.

- Petalas, M. A., Hastings, R. P., Nash, S., Hall, L. M., Joannidi, H., \& Dowey, A. (2012). Psychological Adjustment and Sibling Relationships in Siblings of Children with Autism Spectrum Disorders: Environmental Stressors and the Broad Autism Phenotype. Research in Autism Spectrum Disorders, 6(1), 546-555. doi:10.1016/j.rasd.2011.07.015 
- Poston, D., Turnbull, A., Park, J., Mannan, H., Marquis, J., \& Wang, M. (2003). Family Quality of Life: A Qualitative Inquiry. Mental Retardation, 41(5), 313-328. doi:10.1352/0047$6765(2003) 41<313$ :fqolaq $>2.0 . c 0 ; 2$

- Rodríguez-Fernández, A., Ramos-Díaz, E., Madariaga, J. M., Arrivillaga, A., \& Galende, N. (2016). Steps in the Construction and Verification of an Explanatory Model of Psychosocial Adjustment. European Journal of Education and Psychology, 9(1), 20-28. doi:10.1016/j.ejeps.2015.11.002

- Tomeny, T. S., Ellis, B. M., Rankin, J. A., \& Barry, T. D. (2017). Sibling Relationship Quality and Psychosocial Outcomes Among Adult Siblings of Individuals with Autism Spectrum Disorder and Individuals with Intellectual Disability without Autism. Research in Developmental Disabilities, 62, 104-114. doi:10.1016/j.ridd.2017.01.008

- Tsai, H.-W. J., Cebula, K., \& Fletcher-Watson, S. (2016). Influences on the Psychosocial Adjustment of Siblings of Children with Autism Spectrum Disorder in Taiwan and the United Kingdom. Research in Autism Spectrum Disorders, 32, 115-129. doi:10.1016/j.rasd.2016.09.007

- Tudor, M. E., Rankin, J., \& Lerner, M. D. (2018). A Model of Family and Child Functioning in Siblings of Youth with Autism Spectrum Disorder. Journal of Autism and Developmental Disorders, 48(4), 1210-1227. doi:10.1007/s 10803-017-3352-5 
- Vanderkerken, L., Heyvaert, M., Onghena, P., \& Maes, B. (2019). The Relation Between Family Quality of Life and the Family-Centered Approach in Families with Children with an Intellectual Disability. Journal of Policy and Practice in Intellectual Disabilities. doi:10.1111/jppi. 12317

- Walton, K. M., \& Ingersoll, B. R. (2015). Psychosocial Adjustment and Sibling Relationships in Siblings of Children with Autism Spectrum Disorder: Risk and Protective Factors. Journal of Autism and Developmental Disorders, 45(9), 2764-2778. doi:10.1007/s 10803-015-2440-7

- World Health Organization (2019). Autism Spectrum Disorders. Retrieved from https://www.who.int/news-room/factsheets/detail/autism-spectrum-disorders. 